\title{
Functional Relationships between the Hippocampus and Dorsomedial Striatum in Learning a Visual Scene-Based Memory Task in Rats
}

\author{
[D Sébastien Delcasso, ${ }^{1}$ Namjung Huh, ${ }^{2}$ Jung Seop Byeon, ${ }^{1}$ Jihyun Lee, ${ }^{1}{ }^{\oplus}$ Min Whan Jung, ${ }^{2,3}$ and $\odot$ Inah Lee ${ }^{1}$ \\ ${ }^{1}$ Department of Brain and Cognitive Sciences, Seoul National University, Seoul, 151-742, Korea, ${ }^{2}$ Center for Synaptic Dysfunctions, Institute for Basic \\ Science, Korea Advanced Institute of Science and Technology, Daejeon, 305-701, Korea, and ²Department of Biological Sciences, Korea Advanced Institute \\ of Science and Technology, Daejeon, 305-701, Korea
}

The hippocampus is important for contextual behavior, and the striatum plays key roles in decision making. When studying the functional relationships with the hippocampus, prior studies have focused mostly on the dorsolateral striatum (DLS), emphasizing the antagonistic relationships between the hippocampus and DLS in spatial versus response learning. By contrast, the functional relationships between the dorsomedial striatum (DMS) and hippocampus are relatively unknown. The current study reports that lesions to both the hippocampus and DMS profoundly impaired performance of rats in a visual scene-based memory task in which the animals were required to make a choice response by using visual scenes displayed in the background. Analysis of simultaneous recordings of local field potentials revealed that the gamma oscillatory power was higher in the DMS, but not in CA1, when the rat performed the task using familiar scenes than novel ones. In addition, the CA1-DMS networks increased coherence at $\gamma$, but not at $\theta$, rhythm as the rat mastered the task. At the single-unit level, the neuronal populations in CA1 and DMS showed differential firing patterns when responses were made using familiar visual scenes than novel ones. Such learning-dependent firing patterns were observed earlier in the DMS than in CA1 before the rat made choice responses. The present findings suggest that both the hippocampus and DMS process memory representations for visual scenes in parallel with different time courses and that flexible choice action using background visual scenes requires coordinated operations of the hippocampus and DMS at $\gamma$ frequencies.

Key words: basal ganglia; decision making; hippocampus; memory; place cells; spatial representation

\section{Introduction}

To make a contextual response, an animal should first recognize its surrounding environment and decide which behavior is appropriate in a given context. The hippocampus is important for processing environmental background (Kim and Fanselow, 1992; Anderson and Jeffery, 2003), and the striatum is critical for action selection (Balleine et al., 2007; Braun and Hauber, 2011). Specifically, the hippocampus is critical for making use of visual stimuli distally placed in the background to guide behavior, and rats with malfunctioning hippocampi find it difficult to use such cues in memory tasks (Prusky et al., 2004; Gold and Kesner, 2005; Kim and Lee, 2011). Furthermore, single-unit recording studies show that visual cues in

\footnotetext{
Received Feb. 12, 2014; revised Sept. 26, 2014; accepted 0ct. 5, 2014.

Author contributions: J.S.B. and I.L. designed research; S.D., J.S.B., and J.L. performed research; S.D., N.H., M.W.J., and I.L. analyzed data; M.W.J. and I.L. wrote the paper.

This work was supported by National Research Foundation (NRF) (BK21 + program 5286-2014100; SRC 20100027941), the Brain Research Program (NRF-2013M3C7A1044017 and 2013R1A1A2062882), WCU program (R3210142), and R01 MH079971 (National Institutes of Health) to I.L., and the Research Center Program of the Institute for Basic Science to M.W.J.

The authors declare no competing financial interests.

Correspondence should be addressed to Dr. Inah Lee, Department of Brain and Cognitive Sciences, Seoul National University, Seoul, Korea 151-742. E-mail: lee.inah@gmail.com.

S. Delcasso's current address: McGovern Institute for Brain Sciences, Massachusetts Institute of Technology, Cambridge, MA 02139 .

DOI:10.1523/JNEUROSCI.0622-14.2014

Copyright $\odot 2014$ the authors $\quad 0270-6474 / 14 / 3415534-14 \$ 15.00 / 0$
}

the background influence neural firing in the hippocampus (Anderson and Jeffery, 2003; Dombeck et al., 2010).

Once processed, memory representations in the hippocampus should be associated with proper actions compatible with the contextual stimuli in the background, and a growing body of evidence suggests that the striatum is one of the regions where such action-selection processes are realized (Kimchi and Laubach, 2009; Braun and Hauber, 2011). It remains largely unknown, however, how these two cognitive processes are implemented between the two brain regions when appropriate decisions are made. The striatum is composed of anatomically heterogeneous subregions (Alexander and Crutcher, 1990; Voorn et al., 2004; Thorn et al., 2010). It is hypothesized that the dorsolateral and dorsomedial subregions of the striatum (DLS and DMS, respectively) can be distinguished from each other (Devan et al., 1999; Johnson et al., 2007; Thorn et al., 2010), with the DLS being more important for habitual memory and the DMS for flexibly associating actions toward goals and their outcomes. It is suggested that the DLS belongs to the sensorimotor learning system, maintaining rich connections with somatosensory and motor cortices. Accordingly, the DLS supports egocentric habit memory and is known to maintain competitive relationships with the allocentric memory system, such as the hippocampus in a spatial memory task (Packard and McGaugh, 1996; Devan et al., 1999). Compared with the DLS, the functional 
A

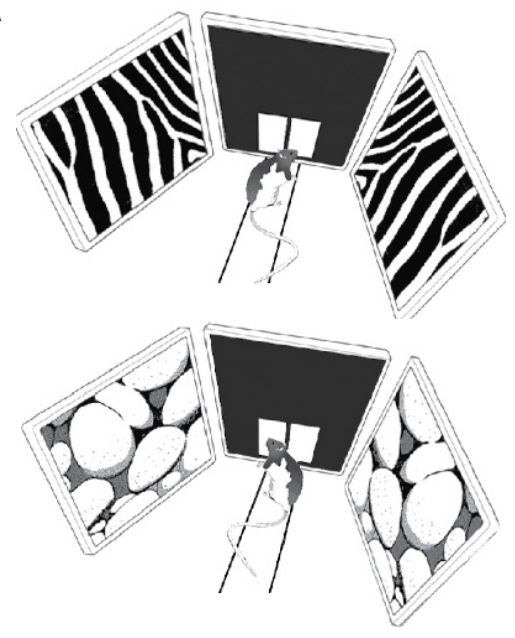

B

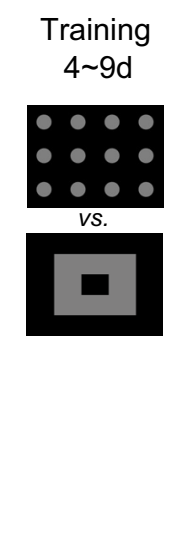

C

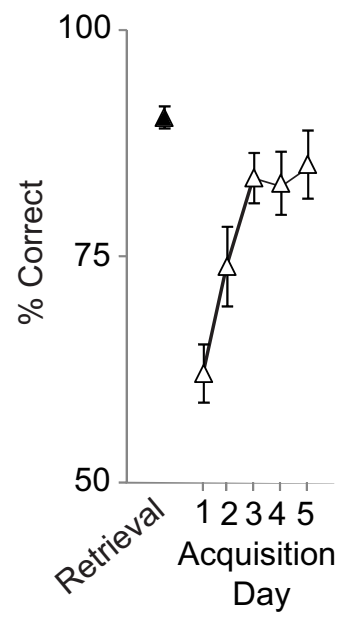

D

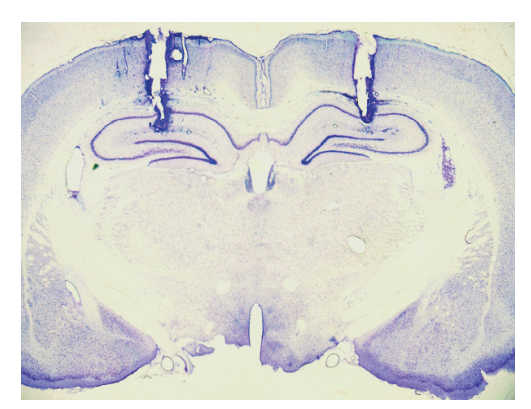

E

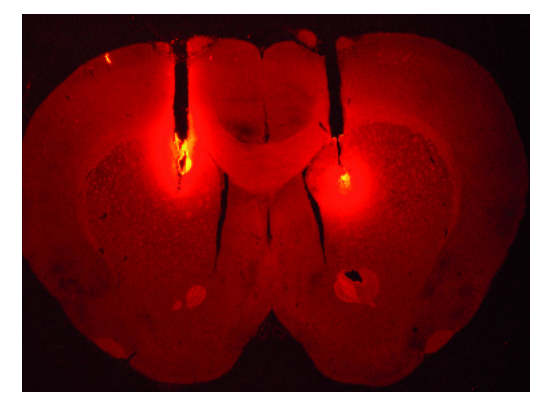

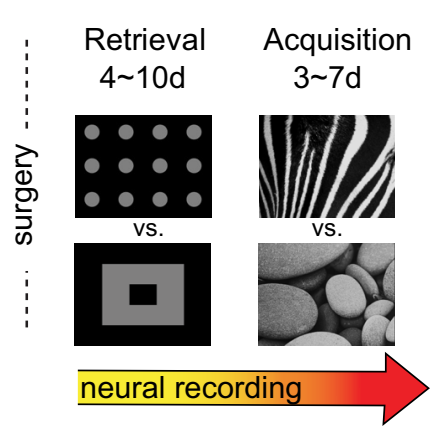

$\mathbf{F}$

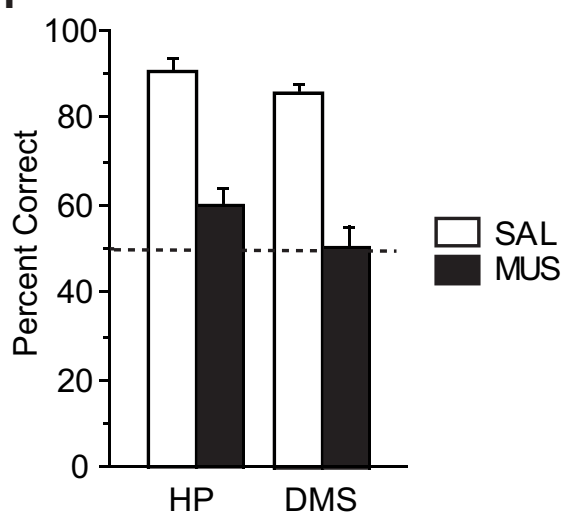

Figure 1. Visual scene memory task and performance deficits with hippocampal and DMS inactivations. $A$, lllustration of the behavioral task. The start box is not shown. The rat was required to touch between left and right discs by using the visual scene stimuli (top: zebra-striped pattern; bottom: pebbles pattern) presented in the peripheral LCD screens as a cue. $\boldsymbol{B}$, Experimental schedules. After surgery, neural recordings were made using the same stimuli used during the training period for several days (retrieval), followed by recording with novel scene stimuli (acquisition). $\boldsymbol{C}$, Behavioral performance. Performance dropped initially when familiar visual backgrounds (retrieval) were replaced with novel visual stimuli (acquisition), but rats quickly relearned the task in $3 \mathrm{~d}$ on average. Data are mean \pm SEM. D, Cannula positions in the dorsal hippocampus. Data from Kim et al. (2012). $\boldsymbol{E}$, Cannula positions and the diffusion of fluorescent muscimol in the DMS. $\boldsymbol{F}$, Performance with either saline (SAL) or muscimol (MUS) injected in the dorsal hippocampus (HP) or in the DMS. The dotted line represents chance-level performance. Hippocampal data are from our previous study (Kim et al., 2012). Note the severe deficits when either the hippocampus or DMS was inactivated with muscimol compared with the vehicle conditions. Data are mean \pm SEM.

relationships between the hippocampus and DMS remain largely unknown. The DMS, often considered an "associative" part of the striatum (Yin et al., 2009; Thorn et al., 2010), lacks the sensorimotor connectivity found in DLS. The DMS instead shows strong connections with other areas, such as the prefrontal and visual areas, as well as the limbic circuits (McGeorge and Faull, 1989; Saint-Cyr et al., 1990; Reep et al., 2003; Voorn et al., 2004; Schulz et al., 2009; Devan et al., 2011; Mailly et al., 2013). The literature suggests that both the DMS and hippocampus are functionally important for the acquisition of spatial memory and during flexible spatial behavior (Devan et al., 1999; Johnson et al., 2007; Brown et al., 2012), but supporting physiological evidence is scarcely found. Here, we simultaneously recorded the singleunit activity and local field potential (LFP) in the CA1 subfield of the dorsal hippocampus and DMS as rats made conditional choices in a familiar or novel visual environment.

\section{Materials and Methods}

\section{Subjects}

Eleven Long-Evans rats (male, 300-400 g) were used in the study. Food was controlled to maintain the body weight at $\sim 85 \%$ of the free-feeding weight. Water was available ad libitum. All protocols conformed to the
National Institutes of Health Guide for the Care and Use of Laboratory Animals and the Institutional Animal Care and Use Committee of the Seoul National University.

\section{Behavioral apparatus}

A linear track with a start box located at one end was used in the study (Fig. 1A). There was an array of three monitors at the other end of the linear track. The angle made by the center monitor's lateral edges and the adjoining lateral edge of each peripheral monitor was $98^{\circ}$. The 15 inch monitor in the center of the LCD array was equipped with an infrared touchscreen panel to record the animals' touch responses. A transparent acrylic panel with two rectangular holes was overlaid with the touchscreen panel to restrict the rat's response within certain areas of the touchscreen panel. The response windows were separated by a small piece of transparent acrylic divider to facilitate discrete and explicit choice behavior. A white rectangular image ("response box" hereafter, each $4.6 \times 8.6 \mathrm{~cm}$ ) over a black background appeared in the touchscreen panel (with cut opening for each response box, each $6 \times 10 \mathrm{~cm}$; the two response areas separated by a 2 -cm-wide acrylic divider to facilitate discrete choices), aligned with the response window. Although each response area cut in the acrylic panel was $6 \times 10 \mathrm{~cm}$ in size, the rat touched mostly a common area in the response box (i.e., the closest spot from the vertical acrylic divider) to register its response as quickly and efficiently as possible. 
The rat was required to touch one of the response boxes to obtain a reward by using the visual scene stimuli displayed on the 17 inch monitors positioned on both sides of the central touchscreen monitor (Fig. $1 A$ ). When a correct response was made, the rat received a ball-shaped chocolate cereal reward in a food tray below the central monitor. There were three optical fiber sensors installed along the track (start, middle, and end), and an additional sensor was placed at the entrance of the food tray. Breakage of each sensor beam and touch signals were converted into TTL signals. The incoming TTL signals were redirected to the data acquisition machine for instantaneous time-stamping. Custom-written software using MATLAB (MathWorks) and the Psychtoolbox controlled the visual stimuli and transmitted TTL signals associated with the visual stimuli, trial correctness, and response positions relative to the touch screen directly to the data acquisition machine. The apparatus was located in a circular curtained area in a soundproof room. A digital CCD camera attached to the ceiling recorded the rat's head positions and orientations at $30 \mathrm{~Hz}$. A halogen light was installed immediately adjacent to the CCD camera to illuminate the room at 0.2 lux. Two loud speakers provided white noise $(80 \mathrm{~dB})$ during behavioral experiments. The luminance of the visual scene was set at 3.8 lux, when measured by a luminance meter.

\section{Behavioral paradigm}

Once rats were shaped to touch a stimulus displayed on the touchscreen, they were trained in a main task. In the task, a trial started as the experimenter opened the guillotine door of the start box, after displaying one of the two visual scenes (polka-dot pattern and square pattern) on the peripheral monitors (Fig. 1B). The visual scenes were constructed in grayscale, and both scenes were equalized with respect to luminance (3.8 lux). Once exiting the start box, the rat ran toward the touchscreen at the end of the track. The rat was required to touch one of the response boxes displayed on the touchscreen monitor to obtain a reward. Touching a correct response box resulted in an immediate sound feedback $(2 \mathrm{kHz}$, $3 \mathrm{~s}, 83 \mathrm{~dB}$ ), followed by a piece of cereal dispensed in the food tray. The rat was trained to return to the start box with a food reward. When the rat chose a wrong response box, it produced an immediate error sound $(0.2$ $\mathrm{kHz}, 3 \mathrm{~s}, 83 \mathrm{~dB}$ ) with no reward; and if the rat did not return to the start box voluntarily, it was gently guided back with a plastic panel. An intertrial interval of $4 \mathrm{~s}$ was given when the rat was in the start box after a correct trial, and a longer intertrial interval (12 s) was imposed after an incorrect choice. Fifty trials were given in a behavioral session. The presentation order of visual scenes was pseudo-randomized (and counterbalanced) to assure that both scenes appeared equally within a session. In addition, one scene was never presented more than three trials in a row. Once the performance of rats exceeded criterion ( $\geq 75 \%$ correct for each visual scene), they were implanted with hyperdrives (for the electrophysiological experimental group) or bilateral cannulae (for the druginactivation experiment group). The number of trials increased to 100 once electrophysiological recording sessions began. After the animals reached an asymptotic level of performance, and once sufficient data were collected, the rats learned a new pair of visual scenes (zebra-striped pattern and pebbles pattern) (Fig. $1 B, C$ ).

\section{Surgical implantation of cannulae and hyperdrives}

For the rats $(n=7)$ assigned for the electrophysiological recording experiment, a hyperdrive carrying 24 tetrodes was implanted for physiological recordings of single units and LFPs. Platinum wires $(17.8 \mu \mathrm{m}$ in diameter) were twisted and bonded with heat to make a tetrode. The final impedance of each wire was adjusted to $300-450 \mathrm{k} \Omega$ (measured in gold solution at $1 \mathrm{kHz}$ with an impedance tester). Twenty-four tetrodes were used for recording, and three were used as reference electrodes. For five of seven rats used for the electrophysiological study, the hyperdrive was equipped with two cannulae for carrying separate tetrode bundles. One of the bundles carried 16 tetrodes and two reference electrodes, targeting the dorsal CA1 $(3.5 \mathrm{~mm}$ posterior to bregma and $2.8 \mathrm{~mm}$ lateral to the midline), and the other bundle carried eight tetrodes and one reference electrode that targeted the DMS (1.1 mm anterior to bregma and $1.9 \mathrm{~mm}$ lateral to the midline). The other two animals were implanted with the hyperdrive targeting the CAl subfield only. All tetrodes were lowered down by $1 \mathrm{~mm}$ immediately after the hyperdrive implantation.
For the rats $(n=4)$ assigned for the behavioral study, stainless-steel cannulae (26G, coupled with $32 \mathrm{G}$ dummy cannulae) were implanted bilaterally targeting the DMS ( $1.0 \mathrm{~mm}$ anterior to bregma, midline \pm 2.0 $\mathrm{mm}$, and skull surface $-4.6 \mathrm{~mm}$ used as stereotaxic coordinates) (Fig. $1 D, E)$.

\section{Recording setup}

After a week of recovery, the rat was placed in a custom-built shielded booth located outside the experimental room. While the rat slept in the booth, tetrodes were lowered individually to the target areas over several days. Neural activities were amplified (1000-10,000 times) and digitized (sampled at $32 \mathrm{kHz}$, filtered at $300-6000 \mathrm{~Hz}$ for unit data and at $0.1-450$ $\mathrm{Hz}$ for LFP) using a Digital Lynx data acquisition system. The rat's position in the apparatus and the head direction were tracked by monitoring an array of red and green LEDs attached to the preamplifier headstage that was connected to the hyperdrive. LED lights captured through the ceiling camera were fed to a frame grabber $(30 \mathrm{~Hz}$ sampling rate) in the data acquisition computer. Spiking data from single units, LFP, and position information were time-stamped and stored by the data acquisition machine for offline analyses.

\section{Recording schedule}

Electrophysiological recording sessions with pretrained visual scenes (i.e., retrieval) began as the majority of tetrodes were positioned in the target areas and showed good amounts of single-unit spiking activities. The recording sessions for the retrieval period continued for $4-10 \mathrm{~d}$ (median $6 \mathrm{~d}$ ) to ensure proper sampling of single-unit data. The acquisition period started afterward, during which the same rats were required to learn new scenes (i.e., zebra stripes and pebbles patterns) in the same experimental setup. Recording for the acquisition period continued until the rat exhibited $\geq 75 \%$ correct responses for both scenes for two consecutive days, which took 3-7 d (median $6 \mathrm{~d}$ ), and the performance data from the first $3 \mathrm{~d}$ during acquisition were used for behavioral analysis. Some tetrodes were moved across recording sessions and other tetrodes remained in the same locations, depending on the number of single units recorded in the tetrodes, to maximize the number of simultaneously recorded units.

\section{Drug-injection schedule}

The rats implanted with bilateral DMS cannulae were retrained to criterion once they recovered from surgery (for $\sim 1$ week). Afterward, phosphate-buffered saline was injected as vehicle solution $20 \mathrm{~min}$ before the behavioral testing for $1 \mathrm{~d}$ and muscimol, a GABA-A receptor agonist, was injected on the next day $(0.5 \mu \mathrm{g} / 0.5 \mu \mathrm{l})$ at $10 \mu \mathrm{l} / \mathrm{h}$ rate in the same rats (within-subjects design; Fig. $1 E, F$ ).

\section{Histological verifications of electrode and cannula positions}

After the completion of all recording sessions, the positions of individual tetrodes were marked by electrolytic lesions ( $10 \mu \mathrm{A}$ current for $10 \mathrm{~s}$ ). For the rats used in the behavioral study only, fluorophore-conjugated muscimol was injected $20 \mathrm{~min}$ before killing the animals for the verification of cannula positions. The rat was then killed by injecting a lethal dose of Nembutal, and the brain was transcardially perfused with physiological saline followed by $4 \% \mathrm{v} / \mathrm{v}$ solution of formaldehyde. The frozen brain was sectioned $(30 \mu \mathrm{m})$ later using a sliding microtome. Sections were stained with thionin, and photomicrographs were taken using a digital camera attached to the microscope. The photomicrographs of the tissues were used along with the physiological recording profile for reconstructing tetrode tracks and recording sites in CA1 and DMS. Only the tetrodes located in CA1 and DMS were used for final analyses. For the fluorophore-conjugated muscimol-injected rats, sections were photomicrographed using the fluorescent microscope, and we verified that all cannulae positions were within the DMS in the rats used in the behavioral study (Fig. 1E).

\section{Data analysis}

Unit isolation. Single units simultaneously recorded from the DMS and CA1 (Fig. $2 A, B)$ were isolated offline $(n=3684)$, following the routine procedures described in detail previously (Kim et al., 2011). Briefly, only 


\section{A}
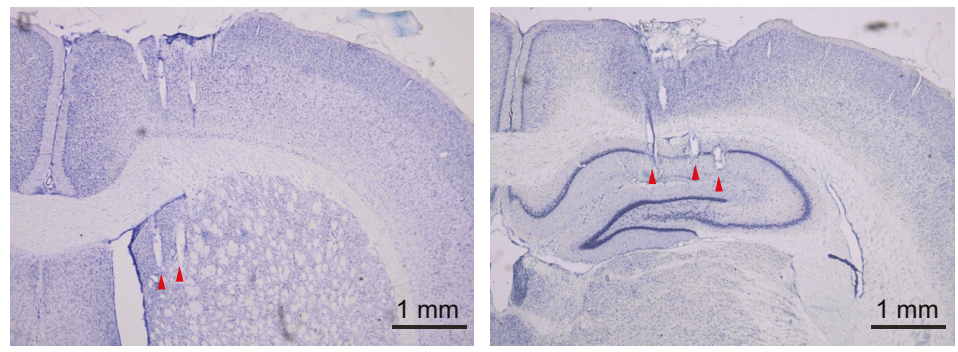

B

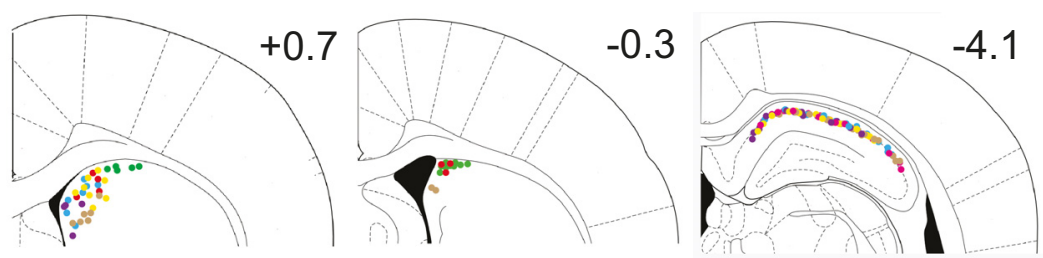

C

D

CA1

DMS
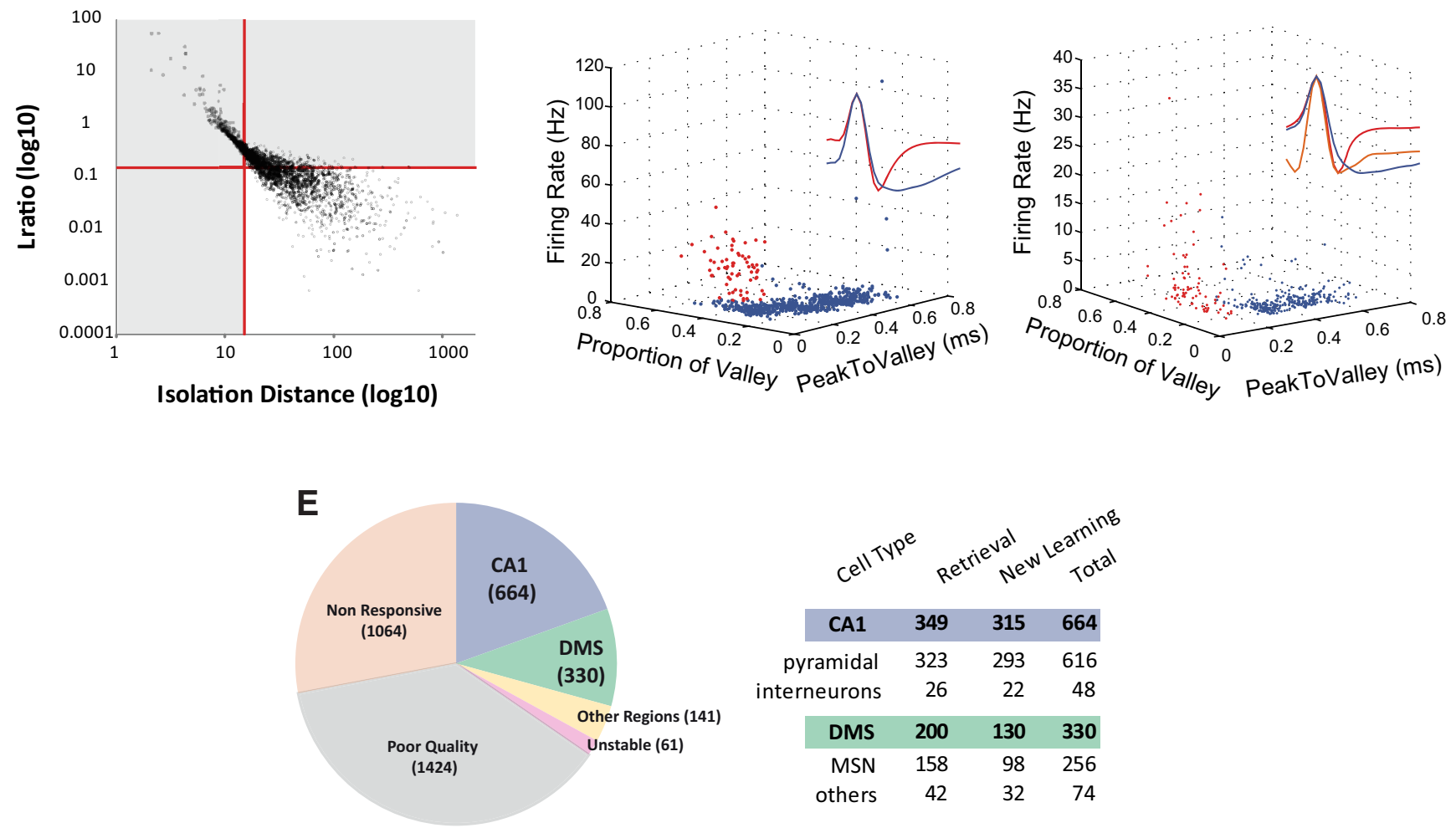

Figure 2. Simultaneous recording of single units in CA1 and DMS. A, Nissl-stained sections of the DMS (left) and hippocampus (right) showing tetrode tracks and tip positions (red arrowheads). $B$, Locations of all tetrode tip from all animals. Colors represent different rats. Numbers indicate the distance from bregma. C, Distribution of cluster quality measures (L-ratio and isolation distance). The units in the gray area were excluded for analyses. D, Putative interneurons (red) were excluded from the analyses based on their waveform characteristics (e.g., peak-to-valley distance) and firing rates in the CA1 and DMS. Insets, Representative average waveforms for putative principal cells (blue) and interneurons (red). $\boldsymbol{E}$, Types of single units recorded in the study. MSN, Medium spiny neuron.

well-isolated clusters on the basis of isolation distance $\geq 15$ and $\mathrm{L}_{\text {ratio }}$ $\leq 0.15$ were used for analysis (Fig. 2C) (Harris et al., 2001; SchmitzerTorbert et al., 2005), and putative interneurons were excluded from analyses on the basis of the following criteria: In the CA1, the units that fired at $>10 \mathrm{~Hz}$ with a peak-to-valley distance of $<300 \mu$ s were classified as interneurons. In the DMS, the units with a peak-to-valley distance of $<250 \mu$ s were classified as interneurons, compared with putative medium spiny neurons (Fig. 2D) (Berke et al., 2004). Tetrodes were adjusted almost daily to maximize the number of units simultaneously recorded per tetrode, and we did not make attempts to identify and maintain same single units across multiple days. Therefore, most of the single units $(72 \%, n=628$ of 872$)$ analyzed in the current study were recorded only once in a single session, judging based on waveform parameters and other tetrode adjustment records (although it is difficult to identify same units recorded across multiple days definitively in extracellular recording). Nonetheless, some neurons $(28 \%, n=244$ of 872$)$ might be re- 
corded across multiple sessions especially when tetrodes were not moved across days.

Analysis for spatial firing patterns. The recording area was scaled down to a $72 \times 48$ pixel space $\left(1\right.$ pixel $\left.=2.17 \mathrm{~cm}^{2}\right)$. Two-dimensional spatial firing rate maps were calculated by dividing the number of spikes per pixel with the total time spent by the rat in the pixel. The firing rate maps were smoothed using an adaptive binning algorithm (Skaggs et al., 1993). For statistical analyses, raw firing rate maps were always used. Spatial information conveyed by spiking activity was measured by calculating spatial information score as follows:

$$
\text { Spatial information (bit/spike) }=\int \lambda(x) \log _{2} \frac{\lambda(x)}{\lambda} p(x) d x
$$

where $x$ is spatial location, $p(x)$ is the probability density for the rat being in place $x, \lambda(x)$ denotes the mean firing rate at location $x$, and $\lambda$ is the overall firing rate of the neuron. The stability of spatial firing patterns between different scenes of a single unit was measured by calculating Pearson's correlation coefficients between the firing rate maps associated with the two scenes. Correlation coefficients were calculated only in those pixels where position traces associated with the different scenes overlapped. The $2 \mathrm{D}$ rate maps were linearized ( 23 bins, 10 pixels/bin) when needed, and a firing field was defined as a set of contiguous bins whose boundaries were marked by the first spatial bins showing $>33 \%$ (start bin) and $<33 \%$ (end bin) of the maximal firing rate.

Scene-based analyses for neural data were conducted only in the areas where motor movements were not significantly different, regardless of the visual scene. For this purpose, for each spatial bin, movement-related measurements ( $x$-coordinates of the position data, speed, and head direction) were averaged across trials within a session. The area of the track in which behaviors were mostly homogeneous across the scene conditions was defined by the spatial bins where the average trajectories associated with the two scenes were separated from each other by $<2$ SDs, and also where speed and head directions were consistent between the visual scenes.

Power spectral and coherence analyses for LFP. Power spectral and coherence analyses were conducted using LFP signals after removing artifacts and electrical noise. Detailed procedures can be found elsewhere (Kim et al., 2011). Briefly, power spectrograms and coherograms were made in CA1 and DMS using the Chronux Toolbox (http://www. chronux.org) and custom-written programs in MATLAB (MathWorks). We defined six major behavioral events as follows: (1) start-box opening (O) when the rat first sampled the visual scene, (2) start (S) when it exited the start box, (3) track end (E) when it reached the end of the track, (4) touch $(\mathrm{T})$ when it made a choice on the touchscreen panel, and (5) food tray in ( Fi) and out (Fo) events. Using a moving window of $200 \mathrm{~ms}$, we analyzed the $500 \mathrm{~ms}$ period surrounding each behavioral event and built both spectrograms and coherograms. Finally, each spectrogram and coherogram was normalized over all sessions.

\section{Results}

\section{Hippocampus and DMS are necessary for visual scene-based} choice behavior

After surgery and recovery, recording commenced while the rat performed the task with familiar visual scenes (i.e., "retrieval") and when learning novel visual scenes (i.e., "acquisition"; Fig. $1 B)$. Rats showed robust performance when presented with the familiar scenes, but, during the acquisition of the novel scenes, the performance dropped significantly on the first day and quickly improved afterward (repeated-measures ANOVA, $F_{(3,18)}=$ 27.7, $p<0.0001$ ) (Fig. 1C). We previously showed that the hippocampus was necessary in the current behavioral paradigm by demonstrating that the inactivation of the dorsal hippocampus with a GABA-A receptor agonist (Fig. 1D), muscimol, severely disrupted performance (Fig. $1 F$ ) (Kim et al., 2012). However, the contribution of the dorsal hippocampus was less obvious in the same study when the task demand was changed to simple asso- ciative learning so that perceiving a visual pattern itself led the rat to the place where a reward was (Prusky et al., 2004). Therefore, the hippocampus was necessary only when the rat could not simply run toward a correct visual pattern to obtain reward because a visual pattern appeared in all three peripheral LCD panels as in the current study. It appears that this task demand for action selection when cued by a visual background also sets a strong demand for the DMS because, when a separate group of rats $(n=$ 4) were injected with muscimol $(0.1 \mu \mathrm{g} / 0.1 \mu \mathrm{l}$ per hemisphere) into the DMS bilaterally (Fig. $1 E$ ), they showed severe performance deficits (repeated-measures ANOVA, $F_{(1,3)}=131.5, p<$ $0.01)$, compared with the vehicle-injected conditions in the same animals (Fig. 1F). These findings strongly demonstrate that the behavioral task used in the current study requires both the dorsal hippocampus and DMS.

\section{Differential changes occur in oscillatory power and coherence between the CA1 and DMS networks during learning}

We examined how the functional relationships changed between the two areas as a result of learning by analyzing LFP signals simultaneously recorded from the CA1 and DMS (Fig. 2A,B). We analyzed LFP signals recorded only from the tetrodes in which well-isolated, putative pyramidal cells (CA1) and medium spiny neurons (DMS) were detected. The oscillatory power in the $\gamma$ frequency $(40-80 \mathrm{~Hz})$ was higher in CA1 than in DMS $\left(F_{(1,140)}=12.93, p<0.001\right)$, whereas no significant difference was found between the two regions in the $\theta$ frequency $(4-12 \mathrm{~Hz}$; $F_{(1,140)}=0.01, p=0.9$; ANOVA) (Fig. $3 A$ ). We found no significant differences in oscillatory power between retrieval and acquisition periods for both $\theta\left(F_{(1,140)}=0.33, p=0.56\right)$ and $\gamma$ $\left(F_{(1,140)}=0.39, p=0.84\right)$ frequencies. However, a significant interaction was found between the region and learning stage in the $\gamma$ frequency $\left(F_{(1,140)}=4.77, p<0.05\right)$, but not in the $\theta$ frequency $\left(F_{(1,140)}=0.34, p=0.56\right)$ (Fig. $3 A$ ). The significant interaction was largely attributable to both the decrease and the increase in $\gamma$ oscillatory power in the DMS and CA1, respectively, during the acquisition period $\left(t_{(70)}=4.33, p<0.0001\right.$ for DMS, $t_{(70)}=4.25, p<0.0001$ for CA1; $t$ test $)$, compared with the retrieval period.

We then examined whether the oscillatory power changed across critical events in the task, including opening of the start box door (i.e., onset of the visual scene stimulus), exiting the start box, reaching the end of the track, choice response to the touch screen, and entry and exit to and from the food tray (denoted as O, S, E, T, Fi, and Fo, respectively, in Fig. 3B). In both CA1 (Fig. $3 B$ ) and DMS (Fig. $3 C$ ), the oscillatory power was overall higher before the rat made its choice (events $\mathrm{O}$ through $\mathrm{E}$ ) than when and after the choices were made (events T through Fo) $\left(t_{(11)}>\right.$ 3.25 and $p$ values $<0.01$ for $\theta$ and $\gamma$ rhythms in CA1 and DMS). There was a significant effect of event on the oscillatory power in both CA1 $\left(F_{(5,50)}=9.46, p<0.0001\right.$ for $\theta, F_{(5,50)}=4.18, p<$ 0.001 for $\gamma)$ and DMS $\left(F_{(5,50)}=9.93, p<0.0001\right.$ for $\theta, F_{(5,50)}=$ $12.69, p<0.001$ for $\gamma$; repeated-measures ANOVA). There was no effect of the learning stage on the oscillatory power changes in CA1 $\left(F_{(1,10)}=0.25, p=0.63\right.$ for $\theta, F_{(1,10)}=0.6, p=0.45$ for $\left.\gamma\right)$ and also in DMS $\left(F_{(1,10)}=0.00, p=0.99\right.$ for $\theta, F_{(1,10)}=1.05, p=$ 0.33 for $\gamma$ ). With respect to the interaction between the region and learning stage, only the $\gamma$ frequency in the DMS showed a significant interaction between the two factors $\left(F_{(5,50)}=3.57, p<\right.$ 0.01 ) (Fig. 3C), but not in the other conditions $(F<0.2, p>$ 0.89 ). The significant interaction in the DMS between the region and learning stage in the $\gamma$ frequency was largely attributable to the heightened $\gamma$ power in the events of the rat sampling a visual 
A

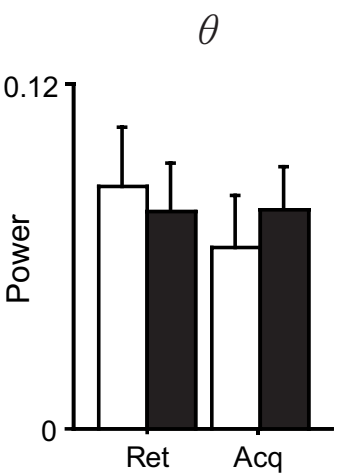

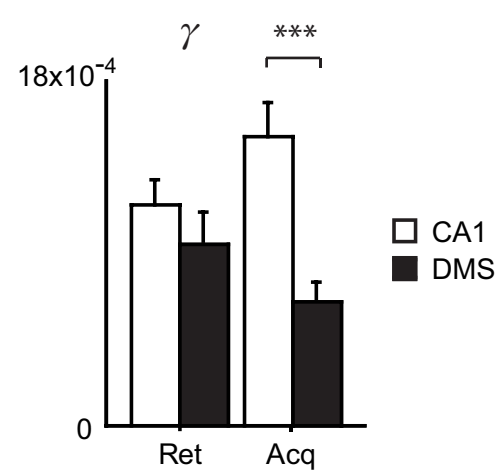

B

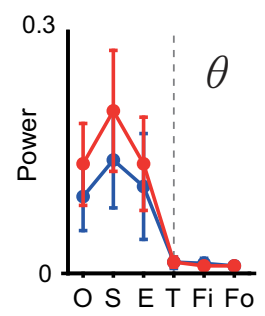

rat 27

rat 49

rat 52

rat 57

rat 69

rat 80
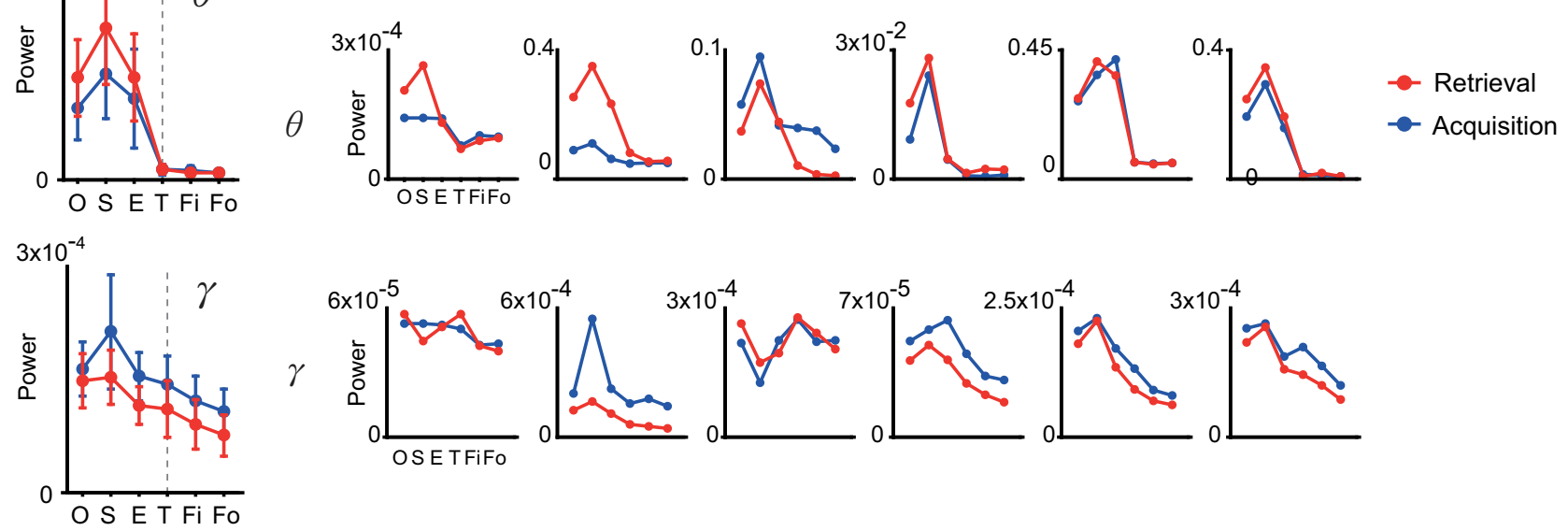

C

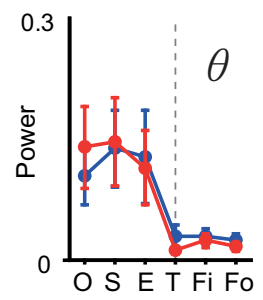

rat 37

rat 49

rat 52

rat 57

rat 69

rat 80

$\theta$

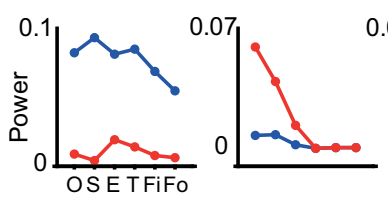

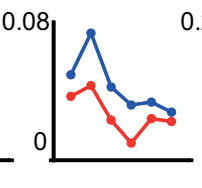
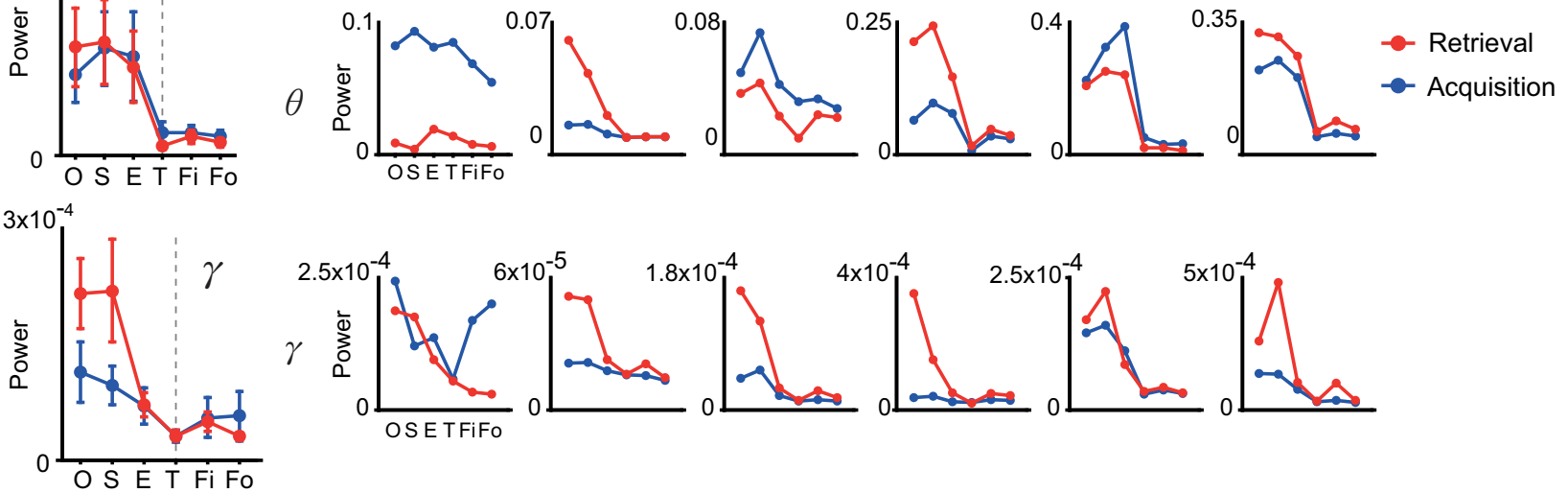

Figure 3. Learning-dependent changes in oscillatory power at $\theta$ and $\gamma$ rhythms in CA1 and DMS. $A$, Changes in the oscillatory power (averaged for all rats) between the retrieval and acquisition periods for $\theta$ and $\gamma$ rhythms. ${ }^{* * *} p<0.0001$. B, C, Oscillatory power changes in CA1 ( $B$ ) and DMS ( $\boldsymbol{C}$ ) for the different frequency bands across different events between the learning stages: 0,0 pening of start box; $\mathrm{S}$, start box exit; $\mathrm{E}$, end of track; $\mathrm{T}$, touchscreen response; Fi, entering food tray; Fo, exiting food tray. Oscillatory power changes across individual rats are also shown beside the averaged graphs. Note the differences in ordinate scales.

scene initially and exiting the start box (events $\mathrm{O}$ and S; Fig. 3C). Paired comparisons showed a trend of difference in $\gamma$ power only at the start-box exit event $\left(t_{(5)}=2.31, p=0.06\right.$, paired $t$ test $)$ between the retrieval and acquisition periods, whereas no other events showed such trend $\left(t_{(5)}=1.78, p=0.13\right.$ for event $\mathrm{O} ; t<$ 0.87 and $p>0.4$ for events T, Fi, and Fo).

It is hypothesized that LFPs from different brain regions are synchronized at $\theta$ or $\gamma$ frequencies as the two areas work together closely (DeCoteau et al., 2007; Montgomery and Buzsáki, 2007; Colgin and Moser, 2010; Kim et al., 2011). We examined whether coherence between CA1 and DMS at the above oscillatory frequencies significantly changed across the learning stages in our task. There was a significant effect of the LFP frequency on the oscillatory coherence between CA1 and DMS $\left(F_{(1,116)}=30.6, p<\right.$ 0.0001 ; repeated-measures ANOVA) (Fig. 4A). The coherence at the $\theta$ frequency was maintained relatively at high levels constantly 


\section{B}
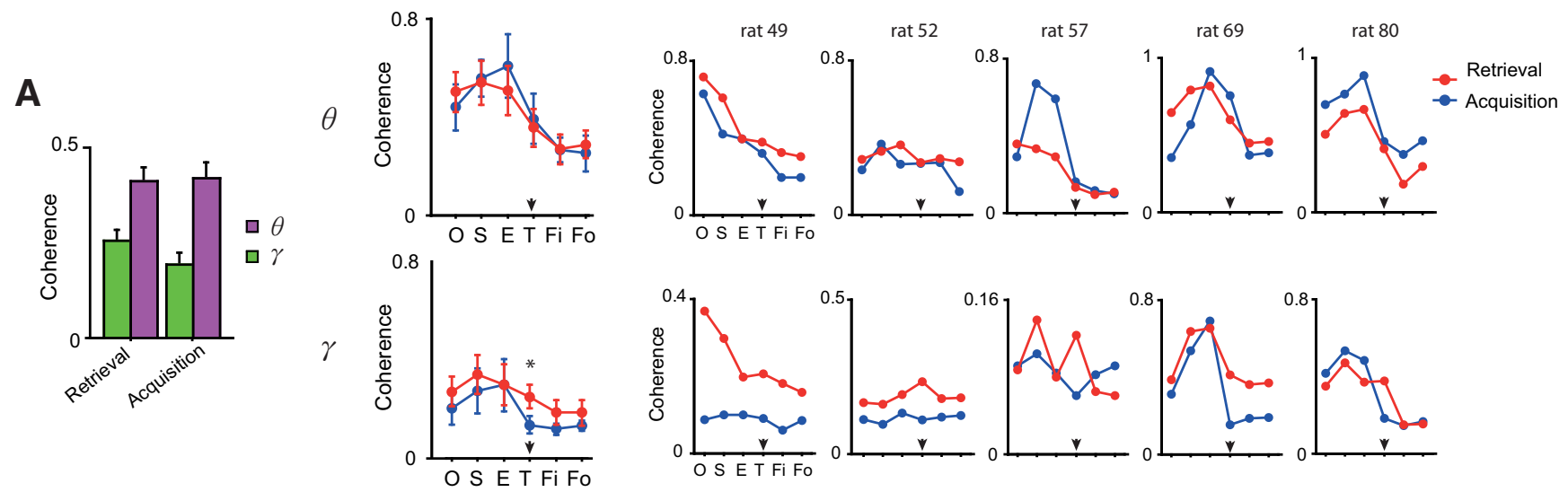

Figure 4. Learning-dependent changes in coherence of $\theta$ and $\gamma$ rhythms in CA1 and DMS. A, Overall coherence in the task between LFPs recorded simultaneously from the CA1 and DMS for the $\theta$ and $\gamma$ frequencies. $\boldsymbol{B}$, Coherograms in $\boldsymbol{A}$ redrawn across individual events between the learning stages. Arrows indicate the moment of scene-based choice behavior (i.e., touchscreen touch). Coherence plots for individual rats are also shown beside the averaged graphs. Note the differences in ordinate scales. ${ }^{*} p<0.05$.

between the retrieval and acquisition stages $\left(t_{(29)}=-0.32, p=0.75\right.$; paired $t$ test), whereas the coherence significantly decreased in the $\gamma$ frequency when the rat performed the task using the novel visual scenes compared with using the welllearned visual stimuli $\left(t_{(29)}=3.79, p<\right.$ 0.001; paired $t$ test). Although the coherence in both frequency bands increased as the rat exited the start box and then decreased as the rat reached the end of the track (significant effect of event, $F_{(5,40)}=$ $11.83, p<0.001$ for $\theta, F_{(5,40)}=5.15, p=$ 0.001 for $\gamma$; repeated-measures ANOVA) (Fig. $4 B$ ), for individual events, the only significant difference between the learning stages was found in the choice event (T) at the $\gamma$ frequency $\left(t_{(4)}=3.7, p<0.05\right.$; $t<1.5, p>0.12$ for the other events; paired $t$ test). A direct comparison of the difference in coherence between the learning stages in $\theta$ rhythm with the learningdependent coherence difference in $\gamma$ rhythm at the choice event failed to reach significance and showed only a trend $\left(t_{(4)}=\right.$ $-2.41, p=0.06)$.

\section{Visual scene influences spatial firing patterns of neurons differentially in CA1 and DMS}

After establishing that the CA1 and DMS were both necessary in the task and showed the learning-dependent oscillatory changes between the two networks, we next investigated the nature of information being communicated between the two areas. Because it is well known that principal neurons in CA1 fire in specific locations (O'Keefe and Dostrovsky, 1971), we first examined whether there were differences between CA1 and DMS with respect to the spatial firing patterns.

The overall spatial firing patterns of DMS neurons in the task were visually indistinguishable from the spatial firing patterns of CA1

C
A DMS

B
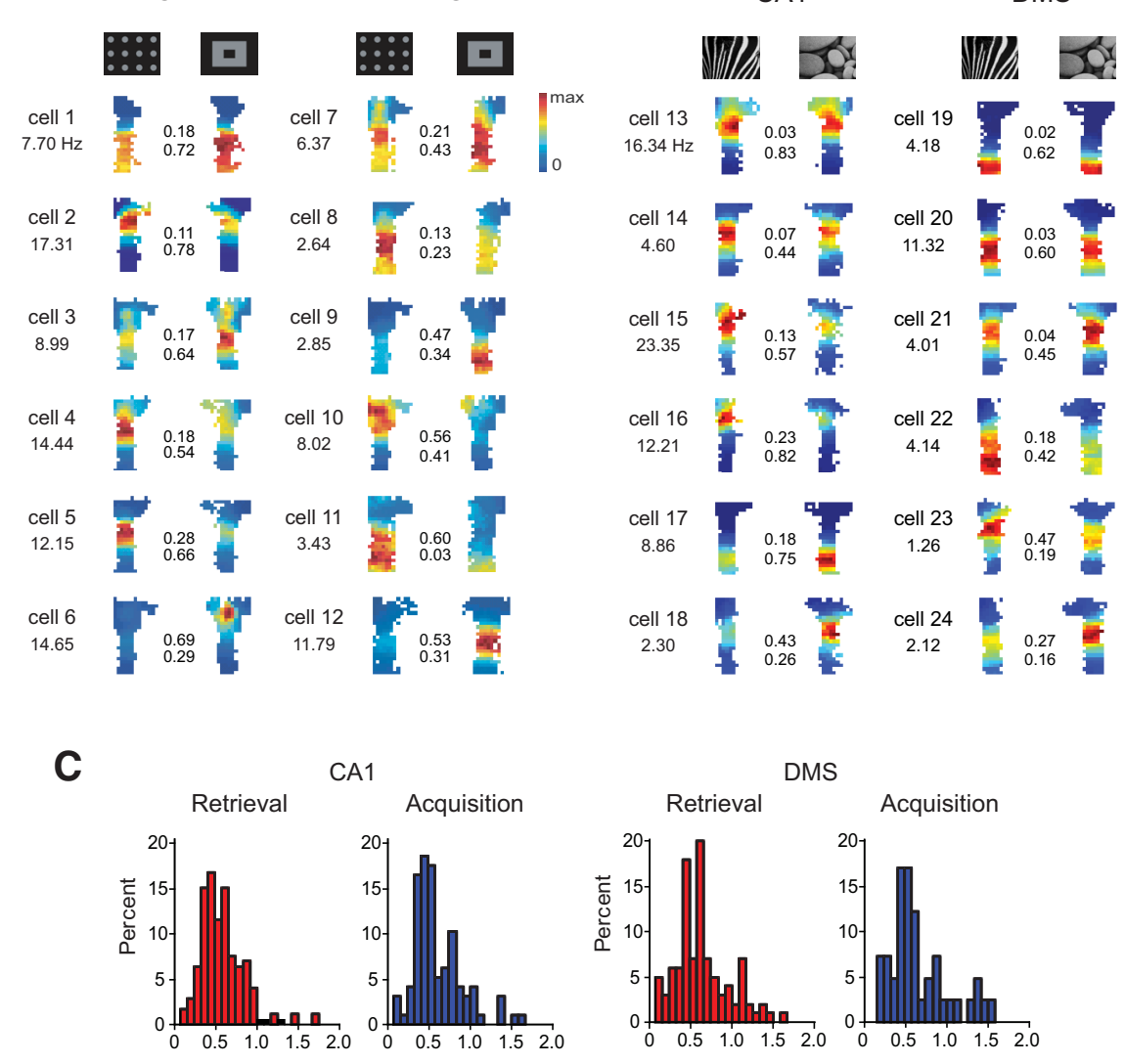

Spatial Information (Bit/Spike)

Figure 5. Spatial firing patterns and scene-associated rate modulation in CA1 and DMS. $A, B$, Representative spatial firing rate maps for different scenes within a session for individual neurons during retrieval $(\boldsymbol{A})$ and acquisition $(\boldsymbol{B})$ periods. The maximal firing rate is given underneath the cell number. The values in-between firing rate maps are the scene selectivity index (top) and the correlation coefficient between the scene-associated rate maps (bottom). C, Distribution of spatial information scores for CA1 and DMS during retrieval and acquisition.

CA1 neurons during the retrieval period (Fig. $5 A$ ). We also observed similar spatial firing patterns during the acquisition period (Fig. $5 B$; units recorded between the retrieval and acquisition periods were not necessarily identical). Some single units recorded from the DMS (Fig. 5A, B, cells 9-12 and 22-24) exhib- 
A

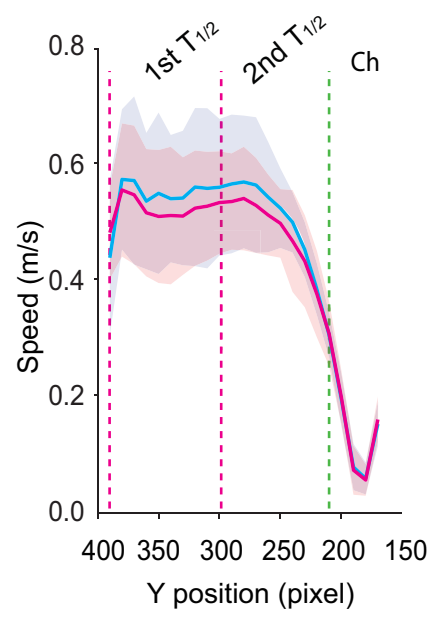

C

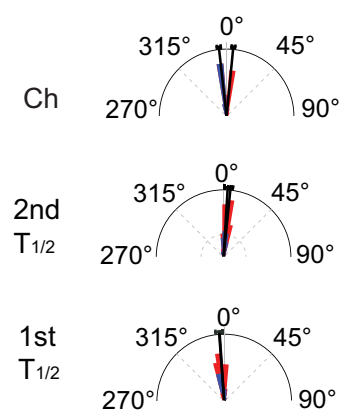

D

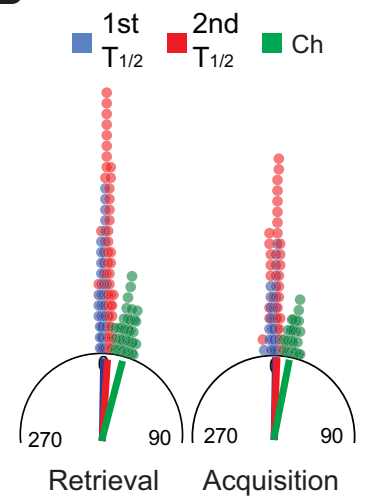

B

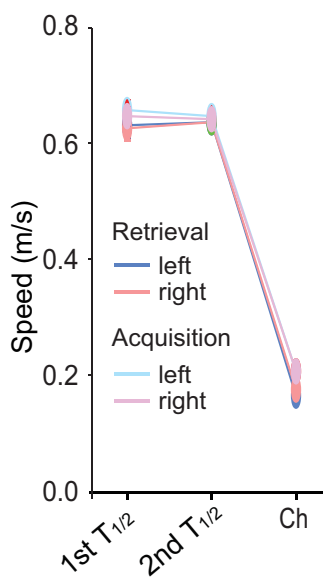

E rat57

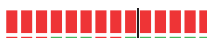

rat69 H什卉

-
-110|1Ht पाППП|П

rat80 H什

Figure 6. Moving speed and head direction. $\boldsymbol{A}, \boldsymbol{B}$, Examples of speed profiles for the left (cyan) and right (magenta) trajectories for a session $(\boldsymbol{A})$ and all sessions combined ( $\boldsymbol{B})$. 1st $\mathrm{T}_{1 / 2}$, , irst half of the track; $2 \mathrm{nd} \mathrm{T}_{1 / 2}$, second half of the track. $C$, Examples of head directions associated with the left and right trajectories for the first half, the second half of the track, and the choice zone (Ch) within a session. $\boldsymbol{D}$, Head directions between left and right trials in each zone for all sessions for all the rats. $\boldsymbol{E}$, Comparisons of head directions between left and right trials for each rat per session for each track zone ( $t$ test). Red squares represent a session showing a significant effect of head direction $(p<0.05)$. Vertical solid line indicates the boundary between the retrieval and acquisition periods in each rat. Note the minimal effects of head direction in the track area.

ited striking selectivity for a particular visual scene, and this was similar to the firing characteristics of some CA1 neurons (cells 4-6 and 16-18). When we examined the spatial information (bit/spike) conveyed by single spikes from the DMS and CA1 across the learning stages (Fig. 5C), we found no significant difference in spatial information quality between the two regions (Kolmogorov-Smirnov test; $D_{(2)}=0.13, p=0.27$ for retrieval; $D_{(2)}=0.17, p=0.39$ for acquisition). These results suggest that neurons in both CA1 and DMS developed fairly localized spatial firing patterns in the current task as has been reported in other tasks previously (O'Keefe and Dostrovsky, 1971; Wiener, 1993; Mizumori et al., 2009).

We then tested whether the spatial firing patterns (measured by firing rate maps) of neurons depended on the visual scene in the background. This was tested by checking whether the rate maps associated with the individual scenes were significantly different in a given session (Pearson's correlation analysis; $\alpha=$ $0.05)$. There was a significant difference between CA1 and DMS with respect to the proportion of neurons whose preferred firing locations were changed between the visual scenes $(n=48$ of 270 in CA1 and $n=52$ of 142 in DMS; $\chi^{2}$ test, $\chi_{(1)}^{2}=20.67, p<$ $0.0001)$. There was no significant difference in the proportion of neurons showing spatial remapping between the acquisition and retrieval periods in the DMS $\left(\chi^{2}\right.$ test, $\left.\chi_{(1)}^{2}=0.95, p=0.32\right)$, whereas there was a trend of more spatial remapping during retrieval than acquisition in CA1 $\left(\chi_{(1)}^{2}=3.66, p=0.06\right)$. We confirmed that the differences in firing patterns associated with different visual scenes were not due to differences in running speed (Fig. 6A, B). Specifically, there were no significant differences in the speed profiles associated with the visual scene $\left(F_{(1,49)}=0.01, p=0.93\right)$ and learning stage $\left(F_{(1,49)}=0.30, p=\right.$ 0.59 ; repeated-measures ANOVA). Head directions were largely maintained consistently throughout the track area but diverged mostly at the choice area as the rat made left-right choices (Fig. $6 C-E)$. The diverging head directions associated with different scenes at the end of the track resulted in a significant difference in the overall head-direction profiles associated with the trials for the left and right responses $\left(F_{(1,49)}=319.93, p<0.001\right)$, but, importantly, there was no significant difference between the retrieval and acquisition periods $\left(F_{(1,49)}=0.40, p=0.4\right.$; repeatedmeasures ANOVA). Furthermore, excluding the choice area where the head directions mostly diverged in our main analyses (e.g., scene-dependent rate modulation occurring differentially between CA1 and DMS) did not change the main results in the current study (see below). We also verified that the position traces associated with different visual scenes overlapped signifi- 
cantly throughout the entire track (Fig. $7 A-C$ ) and only diverged significantly after the rat reached the end of the track, just in front of the touchscreen during both retrieval $\left(t_{(6)}=-11.3, p<0.0001\right)$ and acquisition $\left(t_{(6)}=-12.7, p<0.0001\right.$; one-sample $t$ test) periods (Fig. $7 A, B$, green rectangular areas) as the rat reared and swayed its head sideways.

Because we varied only the nonspatial component (i.e., visual background) of the environment with the location of the apparatus fixed in the recording room, we also checked whether the visual scenes in our task also induced in-field rate modulation (the so-called "rate remapping") (Leutgeb et al., 2006) in CA1 and DMS. We calculated an in-field rate modulation index (taking the absolute value of difference between the average firing rates associated with the different visual scenes, normalized by their sum) only in cells whose scene-associated rate maps showed significant spatial correlations with each other $(\alpha=0.05)$, that is, in cells that fired at relatively constant positions between different visual scenes. The scene manipulation induced greater rate modulation in the DMS than in CA1 (Fig. 8A), showing a significant region effect in $\operatorname{ANOVA}\left(F_{(1,289)}=4.9, p<0.05\right)$. The scene-dependent modulation of firing rate occurred in a learning-dependent manner (Fig. $8 \mathrm{~A}$ ) because it occurred more strongly when rats performed well (both retrieval and the postlearning stage of acquisition) than during the prelearning stage $\left(F_{(2,289)}=4.5, p<0.01\right)$. We verified that all rats whose CA1 and DMS were simultaneously monitored $(n=5)$ showed greater in-field rate modulations in DMS than in CA1 between different scene conditions ( $t$ test per rat; all $p<0.0001$ ). This trend was also observable in each learning stage (retrieval; prelearning and postlearning during acquisition) per animal, although statistical testing could not be performed adequately in most cases because of small sample sizes. Furthermore, when comparing the amount of in-field rate modulation between different learning stages in individual rats, greater rate modulations were observed in both the retrieval and postlearning stages (of acquisition) than in the prelearning stage (of acquisition) in half of the rats (in which the comparison between learning stages per brain region was possible). In the other half of rats, the in-field rate modulation of at least one of the well-learned stages (retrieval or postlearning of acquisition) was higher than that of the postlearning stage of acquisition. These findings make it unlikely that the results in Figure $8 A$ were driven largely by a small subset of animals in the current study. In both CA1 and DMS, there was no significant effect of track position on the scene-based in-field rate modulation (Fig. 8B). The bigger scene-associated in-field rate modulation effect in DMS than in CA1 was also robustly observed $\left(F_{(1,246)}=5.93, p<0.05\right.$, ANOVA), when the scene selectivity was measured by only using the sessions in which no head direction differences were observed (Fig. 8C).

Differential firing for scene-specific choice behavior increases at earlier phases of decision making in DMS than in CA1

We then examined whether learning significantly altered the scene-dependent firing patterns in the neuronal populations in
CA1 and DMS (Fig. 9). In both regions, spatial correlations between the scene-associated firing rate maps were lower (meaning influenced more by the visual scenes) in the high-performance stage (i.e., the retrieval period and the post-learning phase, i.e., $\geq 75 \%$ correct performance, of the acquisition period) than in the low-performance stage (i.e., the prelearning phase of the acquisition period). A two-way ANOVA run on spatial correlation with the region and learning stage (i.e., retrieval, and prelearning and postlearning stages in acquisition) as two main factors showed significant effects of the region $\left(F_{(1,408)}=55.2, p<\right.$ $0.0001)$ and learning stage $\left(F_{(2,308)}=26.3, p<0.0001\right)$ with no significant interaction between the two factors $\left(F_{(2,408)}=0.88\right.$, $p=0.41)$. We verified that similar patterns were observed in the majority of rats (among the rats whose within-subject data were available between the learning stages, $n=4$ of 5 rats in CA1 and $n=3$ of 4 rats in DMS), and the results were not driven by a small subset of animals (data not shown). The significant difference in spatial correlation between the prelearning and postlearning stages within the acquisition period also suggests that the differences in firing patterns between the retrieval and acquisition periods in the current study (see below) could not be merely attributed to physical differences between the visual stimuli used between the learning stages.

We further analyzed whether the effect of learning on spatial firing patterns in CA1 and DMS could be observed at the neuronal population level. Specifically, a population firing rate map was built for each visual scene by aligning all the spatial firing patterns of neurons with respect to their positions (measured by the center of mass of the spatial distribution of spikes) on the track (Fig. $10 A, B$ ). The resulting population rate maps of CA1 maintained similar global spatial firing patterns between the two scenes, whereas the neuronal population in the DMS showed relatively visible disruptions in the spatial firing patterns between the visual scenes in both the retrieval and acquisition periods. We calculated a spatial correlation coefficient at each track position (bin size $=1.5 \mathrm{~cm}$ ) for each pair of population rate vectors associated with different visual scenes (only correct trials used) and 
A

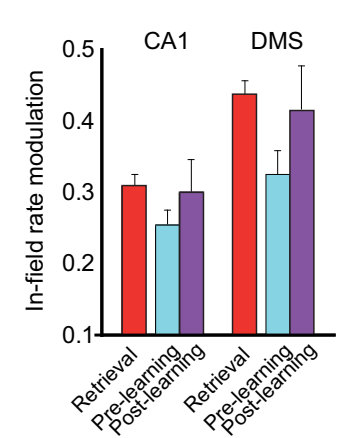

B

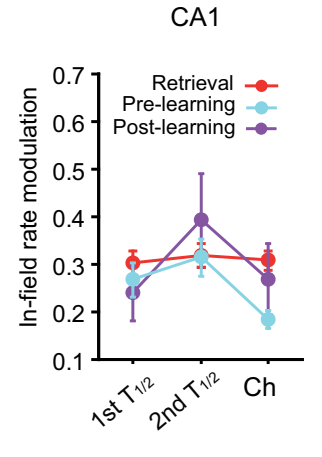

DMS

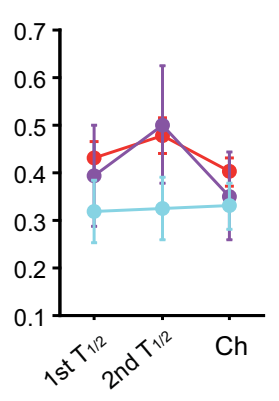

C

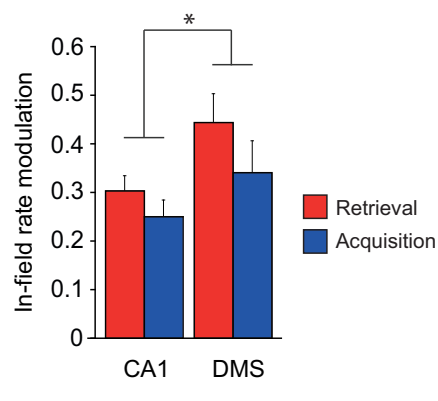

Figure 8. Learning- and scene-dependent rate modulations in CA1 and DMS. $A$, Learning stage-dependent rate modulation in CA1 and DMS. The overall rate modulation amount is bigger in the DMS than in CA1, and bigger rate modulations were observed during well-learned stages (retrieval and postlearning in acquisition) in both regions. $B$, No significant position effect was observed on rate modulation. C, Scene selectivity, calculated in the zones where no significant difference in head direction was observed, still demonstrates a significantly bigger rate modulation in the DMS than in $C A 1 .{ }^{*} p<0.05$.

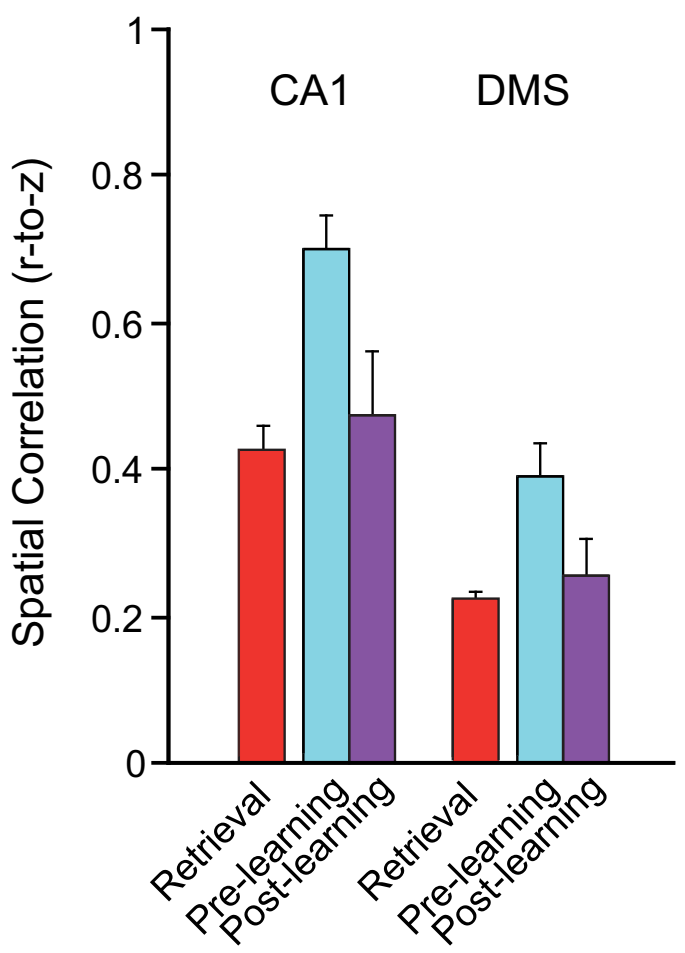

Figure 9. Learning stage-dependent spatial remapping in CA1 and DMS. Note the more pronounced spatial remapping (i.e., lower $r$ - to-z-transformed correlation coefficient) when the performance was higher in learned visual scene conditions (retrieval and postlearning in acquisition) than when the rats were still learning the novel scenes (prelearning). Data are mean \pm SEM.

subtracted the correlation coefficient from 1 to measure the amount of dissimilarity (or orthogonality) between the population spatial representations for different scenes (Fig. 10C). The CA1 population showed highly similar (i.e., rate-map dissimilarity toward 0) spatial firing patterns at the first half of the track (Fig. 10C) in both the acquisition and retrieval stages. During retrieval, however, the population rate maps became gradually dissimilar from each other as the rat entered the second half of the track and diverged further after the end of the track (Fig. 10C, green zone). There was a sudden step-like increase in dissimilarity immediately after the rat reared its head toward a response box to make a choice in the touchscreen (Fig. 10C, green zone). It is possible that this additional divergence of head positions in the touchscreen area might be attributable to such behavioral differences in the choice area. By contrast, during acquisition, spatial firing patterns remained similar between the two scenes throughout the entire track. A sudden increase in rate-map dissimilarity also appeared (as in retrieval, albeit to a lesser amount) as the rat entered the touchscreen area (Fig. 10C).

Compared with CA1, the spatial representations of the DMS population showed a high degree of dissimilarity between the two scenes from the very beginning of the track during retrieval, and the rate maps were maximally different in the second half of the track just before the animal reached the end of the track (Fig. $10 C)$. The relatively high orthogonality between the rate maps of DMS compared with CA1 corroborates our previous findings that DMS neurons were more likely to be influenced by the visual stimulus than CA1 neurons. Calculating the differences in ratemap dissimilarity between the retrieval and acquisition periods showed that, at the first half of the track, the scene-associated rate maps of DMS were more orthogonal from each other during retrieval than in acquisition, whereas this learning effect in DMS was not evident in the second half of the track (Fig. 10D). By contrast, in CA1, the learning-dependent, scene-based orthogonality was observed in the second half of the track, even with the touchscreen choice area being excluded.

In the current study, some of the scene-associated signals in both regions (Fig. 10) might be intermixed with choice action signals. To investigate this, at each position of the track, we tested whether the firing rate distributions associated with the two visual scenes were significantly different from each other in a single neuron ( $p<0.05, t$ test; Fig. $11 A$, "scene"), and the same methods were also applied to left and right goal choices (Fig. 11A, "choice"). In a single neuron, when the firing rate distributions were significantly different from each other $(p<0.05, t$ test) for both variables (visual scene and choice response), we suspected a potential collinearity problem between scene and choice factors and compared the firing rate distributions for correct and error trials while holding one of those factors constant $(p<0.05, t$ test; Fig. 11A). If the firing rate distributions between correct and error trials, all associated with right choices, for example, were different from each other, we rejected the significance for the choice factor (Fig. 11A). By applying these methods for all different conditions exhaustively, we calculated the proportion of neurons in the neuronal population that significantly conveyed information on visual scene and choice response in spiking activ- 
ity along the track. During the retrieval period, the proportions of neurons signaling visual scene and choice action increased similarly in both CA1 and DMS as rats approached the touchscreen area (Fig. 11B), but there were some noticeable differences between the two regions. Most of all, more neurons in the DMS conveyed scene and choice signals (black and gray dotted lines, respectively) in the earlier parts of the track, compared with CA1 (black and gray solid lines for scene and choice, respectively). The locations where the DMS showed bigger proportions of neurons than CA1 were illustrated as orange boxes, and shown in purple boxes when observed more in CA1 than in DMS (filled boxes when statistically significant; $z$-test, $p<0.05$; Fig. $11 B$ ). One can clearly observe that DMS outweighed CA1 in the first half of the track during retrieval. However, the neuronal population in CA1 conveying scene and choice signals abruptly increased as the rat approached the choice area near the touchscreen. We observed similar patterns of increase in DMS for scene and choice variables, but the magnitude of increase was not as big as in CA1 (filled purple boxes). Unlike retrieval, during the acquisition period, the dominance of scene and choice signals in DMS over CA1 in the first half of the track as seen in the retrieval period disappeared (indicated by open squares), and only the neuronal population in CAl exhibited significantly higher choice signals than the DMS at the very end of the track (compare the solid and dotted lines in gray, and see purple squares for "choice") (Fig. 11C).

To examine whether heterogeneous proportions of different types of error trials underlie the results, we repeated the same analysis using only those sessions that contained both types of error trials (mean error rate, $17.1 \%$ in the retrieval phase and $15.7 \%$ in the acquisition phase), and obtained similar results (data not shown). Those neurons selective for a certain combination of scene and choice (i.e., coding both scene and choice) would tend to be classified as coding neither scene nor choice in our analysis (false negative). However, those cells were relatively minor (CA1 retrieval, $n=41,1.5 \%$; CA1 acquisition, $n=12,0.8 \%$; DMS retrieval, $n=37,2.5 \%$; DMS acquisition, $n=8,1.2 \%$ ), and counting them as both scene- and choice-selective neurons did not alter the conclusion (data not shown).

Compared with the results from the spatial correlation analyses (Fig. 10C,D), these findings suggest that the bigger learning effects observed in the DMS (compared with CA1) in the earlier parts of the track, based on spatial correlation, might be largely composed of both scene and choice information, that is, the two critical types of information required for decision making in the current task. However, it is possible that the bigger learning effects seen in the CA1 (compared with the DMS) in the second half of the track (Fig. 10D) might be largely composed of scene signal. During acquisition, in contrast to retrieval, the choice signal in CA1 was not accompanied by a matching level of scene informaDMS.
B
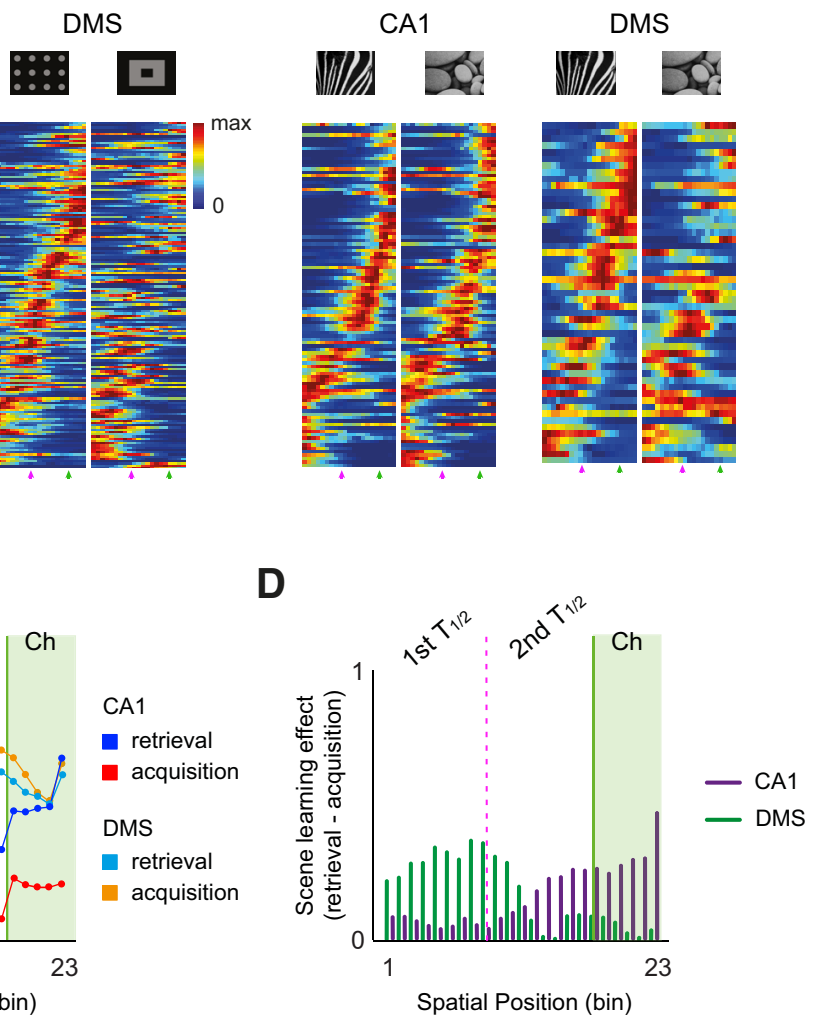

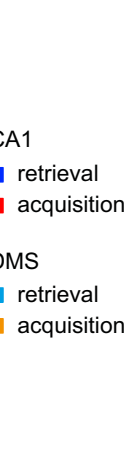

Figure 10. Different scene-learning effects on neuronal populations in CA1 and DMS. $A, B$, Population firing rate maps built by ordering $2 \mathrm{D}$ rate maps associated with the different visual scenes for retrieval $(\boldsymbol{A})$ and acquisition $(\boldsymbol{B})$. Pink arrowheads indicate the (retrieval vs acquisition). Spatial bin of 23 is toward the touchscreen. Pink dotted line indicates the boundary

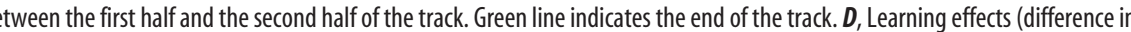
rate-map dissimilarity between retrieval and acquisition) differentially observed at different track positions between the CA1 and

tion (Fig. 11C), which may explain the poorer performance in acquisition than in retrieval. It is important to note that these possibilities of neurons conveying both scene and choice information do not undermine the major findings of the current study; that is, the dissociation of neural firing patterns associated with visual scene manipulations between the hippocampus and DMS across the learning stages.

\section{Discussion}

The results of the current study and our previous study (Kim et al., 2012) strongly suggest that both CA1 and DMS are indispensable in the current task. Our physiological results suggest that spatial representations were more robust in CA1. This suggests that the hippocampal network coded a dynamically changing nonspatial variable (i.e., visual scene) within a fixed spatial frame (i.e., maze in a room), whereas the DMS network might simply code the visual scene as a sensory stimulus not necessarily tied to a spatial cognitive map. This may be because various spatial inputs that contain head direction and path integration information are fed to the hippocampus (McNaughton et al., 1996; Taube, 1998), but not to the DMS (Devan et al., 2011). Furthermore, visual stimuli reach the hippocampus after being highly processed in associative cortical areas, whereas the DMS receives relatively raw inputs from the early visual cortices (Faull et al., 1986; McGeorge and Faull, 1989; Lopez-Figueroa et al., 1995). 


\section{A}

Scene
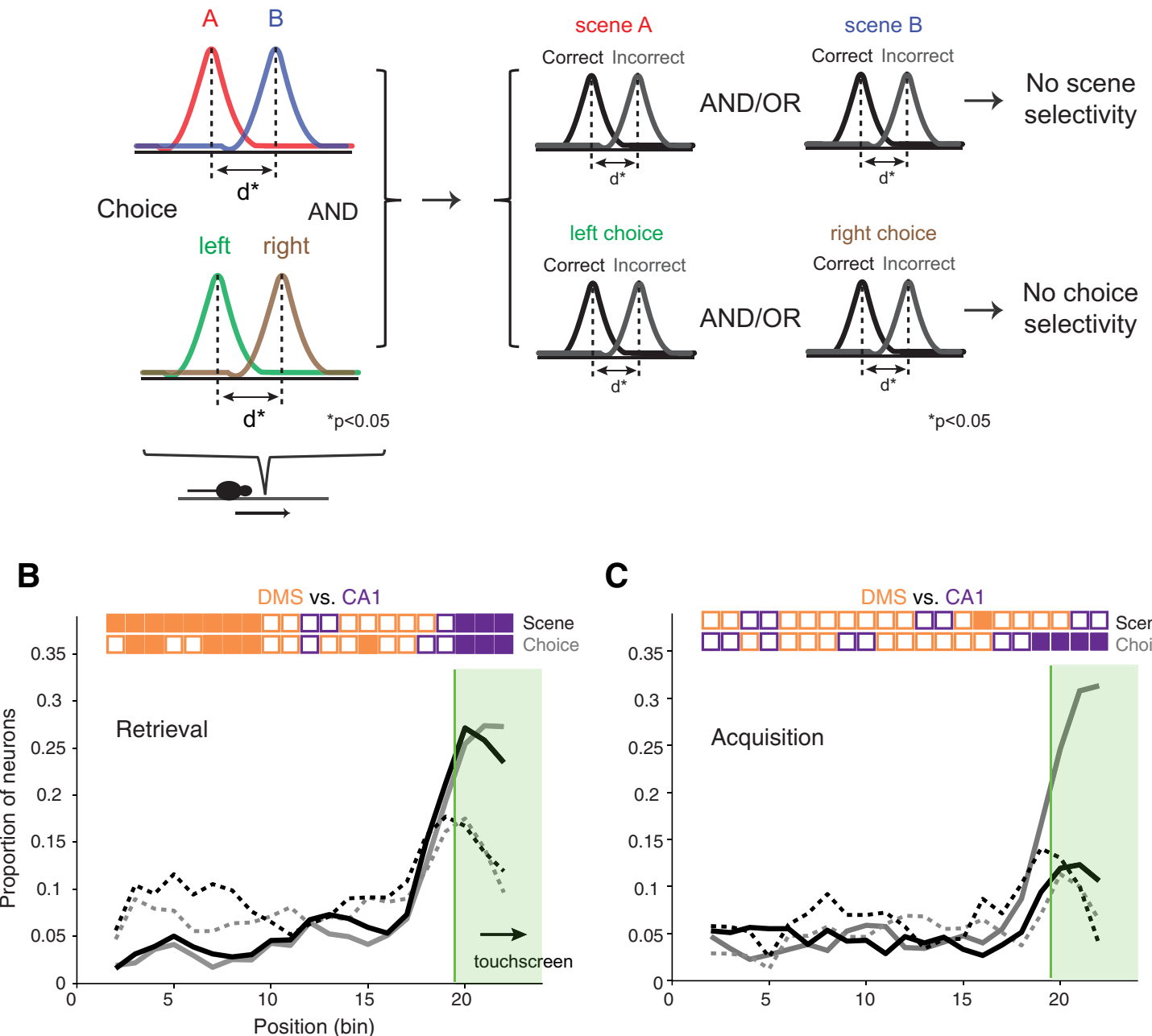

C

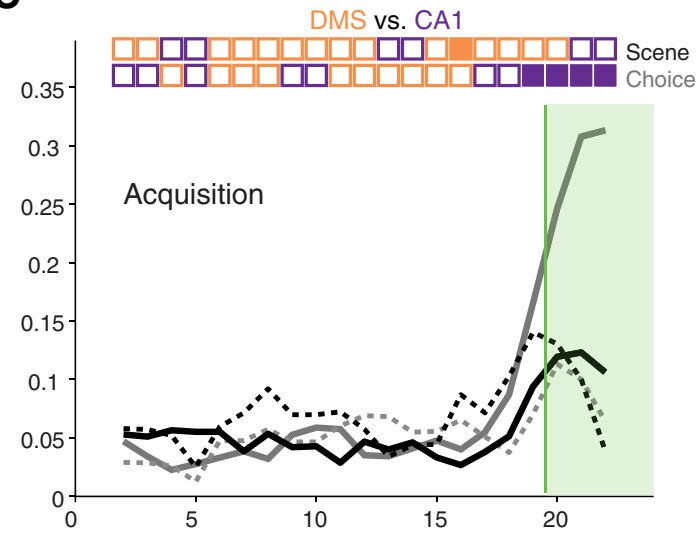

CA1 $\begin{aligned} & \text { Scene } \\ & \text { Choice }\end{aligned} \quad$ DMS $\ldots$..... Scene $\quad \square$ DMS $>$ CA1 $\square{ }^{*} p<0.05$

Figure 11. Learning-dependent changes in scene and choice signals in CA1 and DMS. $A$, Illustration of the statistical comparison of the contributions of scene and choice factors at a given location in the track for a neuron. The firing-rate distributions associated with different scene conditions were statistically compared with each other ( $t$ test), and the same was done for the choice factor (left and right choices). If the neuronal firing distributions were statistically different for both scene and choice factors ( $\mathrm{d}^{*}$ ), collinearity between the two factors was tested explicitly using the firing-rate distributions of correct and incorrect trials while holding one of the factors constant as shown on the right side. B, C, Proportion of neurons in CA1 (solid line) and DMS (dotted lines) that significantly changed firing rates for visual scene (black lines) and choice action (gray lines) during retrieval (B) and acquisition (C). Overlying box plots show which region (CA1 or DMS) demonstrated a larger fraction of neurons at a given spatial position (orange and purple open boxes) for scene and choice factors, and whether the difference was significant (filled boxes; $z$-test, $\alpha=0.05$ ). Green rectangular areas represent the touchscreen response area.

However, the DMS also might receive highly processed visual information from the medial prefrontal cortex (mPFC) and retrosplenial cortex, and the hippocampus also may receive raw visual information from thalamic areas.

The firing in DMS was significantly modulated by visual scenes as the rat first viewed the scene stimuli. Because the DMS has been considered critical for learning goal-directed action and its outcome (Penner and Mizumori, 2012), it is possible that the DMS might prime a proper action-selection system by quickly linking a visual cue with its associated actions as the rat first saw the scene. However, the same stimulus may need to be interpreted differently if the context in which it appears changes and this possibility could be constantly examined by the hippocampus in our task. Such contextual crosscheck of S-R association by the hip- pocampus might become very important, particularly in a situation where background stimuli become ambiguous (O'Reilly and McClelland, 1994; Lee et al., 2004; Leutgeb et al., 2004).

DMS lesions lead to deficits in a task that requires a "flexible" associative priming of an action system in response to sensory cues (Devan and White, 1999; Devan et al., 1999, 2011; Ragozzino et al., 2002). For example, cells in the DMS responded to auditory cues in a conditioned avoidance task, whereas neurons in the DLS coded different "responses" associated with the cues (White and Rebec, 1993). Our task may require flexible channeling of visual information through proper action systems, possibly via the DMS. The literature emphasizes that the mPFC sends direct outputs to the DMS in rodents (Voorn et al., 2004, Mailly et al., 2013), and this suggests the DMS as an integrative center for 
flexibly exercising controls over motor actions contingent upon sensory cues (Voorn et al., 2004; Mizumori et al., 2009). Because the mPFC receives direct connections from CA1 (Swanson, 1981; Jay and Witter, 1991), the mPFC may serve as a critical node for coordinating the information between the hippocampus and DMS when contextual choice is needed. Our previous data showing the involvement of the mPFC in a similar task (Lee and Shin, 2012) strongly suggest that the MPFC may be included as a critical functional unit in scene-based decision making.

Although $\theta$ rhythm has been extensively studied in the hippocampus (Lubenov and Siapas, 2009; Benchenane et al., 2010) and also in the striatum (DeCoteau et al., 2007, Thorn and Graybiel, 2014), the exact functions of $\theta$ oscillation remain unclear. In our task, $\theta$ rhythm was maintained at high levels along the track in both CA1 and DMS, but the power of the $\theta$ oscillation markedly dropped in front of the touchscreen. Similar patterns of changes in $\theta$ power have been reported in the hippocampus and dorsal striatum in an auditory-cued response selection task (DeCoteau et al., 2007; Tort et al., 2008). However, despite the learning-related coordination of the hippocampal and striatal networks at various oscillatory rhythms in the previous memory task (DeCoteau et al., 2007; Tort et al., 2008), the task used in those studies may be categorized as a simple S-R association task that is not likely to require the hippocampus. Some major commonalities and differences are noticeable when comparing the results from the prior studies using such a procedural memory task and the results from the visual scene memory task used in the current study. Most of all, despite the similar rising and falling patterns along the track between the tasks, in the simple S-R task, the $\theta$ power peaked at the motor decision-making point in CA1 and at the starting (i.e., gate-opening) moment in the dorsal striatum, whereas, in our task, the $\theta$ rhythms in both CA1 and DMS were strongest at the time of the rat exiting the start box. The marked drop in $\theta$ power at the touchscreen choice point matches the velocity profile of the rat in our task. This suggests that the modulatory patterns of $\theta$ power might be more associated with movement-related actions than cognitive processes. Furthermore, learning-dependent changes in the coherence between the CA1 and striatal $\theta$ rhythms were previously reported in the procedural memory task, but we were unable to see such phenomenon in our study.

On the other hand, converging pieces of experimental evidence suggest that $\gamma$ oscillation is critical for various cognitive processes, such as the dynamic grouping of individual pieces of information (Singer and Gray, 1995; Colgin and Moser, 2010), directing attention to significant stimuli (Fries et al., 2001; Börgers et al., 2005), transferring information between brain regions (Driver et al., 2007; Colgin et al., 2009), and cross-coupling brain regions during decision making (Tort et al., 2008). Our study suggests that $\gamma$ rhythms are more important than the $\theta$ rhythm in bringing learning-related changes between CA1 and DMS. In our task, $\gamma$-band oscillations $(40-80 \mathrm{~Hz})$ were synchronized more strongly between CA1 and DMS when familiar visual scenes were processed in the retrieval period than the novel ones in the acquisition period. Although further investigations are needed to discover the type of information shared between the two regions at the $\gamma$ frequency, one possibility is that the elemental features of the complex visual stimulus are bound in the hippocampal networks (including the extrahippocampal cortical areas) at the $\gamma$ frequency into a scene representation, and the information is transmitted to the DMS by the same frequency. Alternatively, the visual information associated with the scene, fed to the DMS (for priming the action system) and CA1 (for forming contextual representation) in parallel, may be rapidly cross-examined and shared between the two areas at the $\gamma$ frequency to drive a congruent choice response through the motor system. Another possibility is that flexible switching of information between different scenes is achieved by a third area (e.g., mPFC) for coordinating the hippocampus and DMS via $\gamma$ frequencies for rapidly controlling attention and other cognitive resources.

In conclusion, compared with prior cued conditional discrimination tasks (Reading et al., 1991; Ainge et al., 2012; Hallock et al., 2013), the results of the current study and our previous studies (Kim and Lee, 2011; Kim et al., 2012) suggest that the type of sensory cues (especially elemental vs contextual nature) is critical in determining the recruitment of the hippocampus and possibly the DMS, especially when flexibly switching between different behavioral choices (Eschenko and Mizumori, 2007).

\section{Notes}

Supplemental material for this article is available at http://147.47.203. 200/scene-discrimination-sample.html (visual scene discrimination task). This material has not been peer reviewed.

\section{References}

Ainge JA, Tamosiunaite M, Wörgötter F, Dudchenko PA (2012) Hippocampal place cells encode intended destination, and not a discriminative stimulus, in a conditional T-maze task. Hippocampus 22:534-543. CrossRef Medline

Alexander GE, Crutcher MD (1990) Functional architecture of basal ganglia circuits: neural substrates of parallel processing. Trends Neurosci 13:266271. CrossRef Medline

Anderson MI, Jeffery KJ (2003) Heterogeneous modulation of place cell firing by changes in context. J Neurosci 23:8827-8835. Medline

Balleine BW, Delgado MR, Hikosaka O (2007) The role of the dorsal striatum in reward and decision-making. J Neurosci 28:8161-8165. Medline

Benchenane K, Peyrache A, Khamassi M, Tierney PL, Gioanni Y, Battaglia FP, Wiener SI (2010) Coherent $\theta$ oscillations and reorganization of spike timing in the hippocampal-prefrontal network upon learning. Neuron 66:921-936. CrossRef Medline

Berke JD, Okatan M, Skurski J, Eichenbaum HB (2004) Oscillatory entrainment of striatal neurons in freely moving rats. Neuron 43:883-896. CrossRef Medline

Börgers C, Epstein S, Kopell NJ (2005) Background $\gamma$ rhythmicity and attention in cortical local circuits: a computational study. Proc Natl Acad Sci U S A 102:7002-7007. CrossRef Medline

Braun S, Hauber W (2011) The dorsomedial striatum mediates flexible choice behavior in spatial tasks. Behav Brain Res 220:288-293. CrossRef Medline

Brown TI, Ross RS, Tobyne SM, Stern CE (2012) Cooperative interactions between hippocampal and striatal systems support flexible navigation. Neuroimage 60:1316-1330. CrossRef Medline

Colgin LL, Moser EI (2010) Gamma oscillations in the hippocampus. Physiology 25:319-329. CrossRef Medline

Colgin LL, Denninger T, Fyhn M, Hafting T, Bonnevie T, Jensen O, Moser MB, Moser EI (2009) Frequency of $\gamma$ oscillations routes flow of information in the hippocampus. Nature 462:353-357. CrossRef Medline

DeCoteau WE, Thorn C, Gibson DJ, Courtemanche R, Mitra P, Kubota Y, Graybiel AM (2007) Learning-related coordination of striatal and hippocampal $\theta$ rhythms during acquisition of a procedural memory task. Proc Natl Acad Sci U S A 104:5644-5649. CrossRef Medline

Devan BD, White NM (1999) Parallel information processing in the dorsal striatum: relation to hippocampal function. J Neurosci 19:2789-2798. Medline

Devan BD, McDonald RJ, White NM (1999) Effects of medial and lateral caudate-putamen lesions on place- and cue-guided behaviors in the water maze: relation to thigmotaxis. Behav Brain Res 100:5-14. CrossRef Medline

Devan BD, Hong NS, McDonald RJ (2011) Parallel associative processing in the dorsal striatum: segregation of stimulus-response and cognitive control subregions. Neurobiol Learn Mem 96:95-120. CrossRef Medline

Dombeck DA, Harvey CD, Tian L, Looger LL, Tank DW (2010) Functional 
imaging of hippocampal place cells at cellular resolution during virtual navigation. Nat Neurosci 13:1433-1440. CrossRef Medline

Driver JE, Racca C, Cunningham MO, Towers SK, Davies CH, Whittington MA, LeBeau FE (2007) Impairment of hippocampal $\gamma(\gamma)$-frequency oscillations in vitro in mice overexpressing human amyloid precursor protein (APP). Eur J Neurosci 26:1280-1288. CrossRef Medline

Eschenko O, Mizumori SJ (2007) Memory influences on hippocampal and striatal neural codes: effects of a shift between task rules. Neurobiol Learn Mem 87:495-509. CrossRef Medline

Faull RL, Nauta WJ, Domesick VB (1986) The visual cortico-striato-nigral pathway in the rat. Neuroscience 19:1119-1132. CrossRef Medline

Fries P, Reynolds JH, Rorie AE, Desimone R (2001) Modulation of oscillatory neuronal synchronization by selective visual attention. Science 291: 1560-1563. CrossRef Medline

Gold AE, Kesner RP (2005) The role of the CA3 subregion of the dorsal hippocampus in spatial pattern completion in the rat. Hippocampus 15: 808-814. CrossRef Medline

Hallock HL, Arreola AC, Shaw CL, Griffin AL (2013) Dissociable roles of the dorsal striatum and dorsal hippocampus in conditional discrimination and spatial alternation T-maze tasks. Neurobiol Learn Mem 100:108116. CrossRef Medline

Harris KD, Hirase H, Leinekugel X, Henze DA, Buzsáki G (2001) Temporal interaction between single spikes and complex spike bursts in hippocampal pyramidal cells. Neuron 32:141-149. CrossRef Medline

Jay TM, Witter MP (1991) Distribution of hippocampal CA1 and subicular efferents in the prefrontal cortex of the rat studied by means of anterograde transport of Phaseolus vulgaris-leucoagglutinin. J Comp Neurol 313:574-586. CrossRef Medline

Johnson A, Van der Meer MAA, Redish AD (2007) Integrating hippocampus and striatum in decision making. Cur Opin Neurobiol 17:692-697. CrossRef Medline

Kim J, Lee I (2011) Hippocampus is necessary for spatial discrimination using distal cue-configuration. Hippocampus 21:609-621. CrossRef Medline

Kim JJ, Fanselow MS (1992) Modality-specific retrograde amnesia of fear. Science 256:675-677. CrossRef Medline

Kim J, Delcasso S, Lee I (2011) Neural correlates of object-in-place learning in hippocampus and prefrontal cortex. J Neurosci 31:16991-17006. CrossRef Medline

Kim S, Lee J, Lee I (2012) The hippocampus is required for visually cued contextual response selection, but not for visual discrimination of contexts. Front Neurosci 6:66. CrossRef Medline

Kimchi EY, Laubach M (2009) Dynamic encoding of action selection by the medial striatum. J Neurosci 29:3148-3159. CrossRef Medline

Lee I, Shin JY (2012) Medial prefrontal cortex is selectively involved in response selection using visual context in the background. Learn Mem 19: 247-250. CrossRef 22595688

Lee I, Yoganarasimha D, Rao G, Knierim JJ (2004) Comparison of population coherence of place cells in hippocampal subfields CA1 and CA3. Nature 430:456-459. CrossRef Medline

Leutgeb S, Leutgeb JK, Treves A, Moser MB, Moser EI (2004) Distinct ensemble codes in hippocampal areas CA3 and CA1. Science 305:12951298. CrossRef Medline

Leutgeb S, Leutgeb JK, Moser EI, Moser MB (2006) Fast rate coding in hippocampal CA3 cell ensembles. Hippocampus 9:765-774. CrossRef Medline

Lopez-Figueroa MO, Ramirez-Gonzalez JA, Divac I (1995) Projections from the visual areas to the neostriatum in rats: a re-examination. Acta Neurobiol Exp 55:165-175. Medline

Lubenov EV, Siapas AG (2009) Hippocampal $\theta$ oscillations are travelling waves. Nature 459:534-539. CrossRef Medline

Mailly P, Aliane V, Groenewegen HJ, Haber SN, Deniau JM (2013) The rat prefrontostriatal system analyzed in 3D: evidence for multiple interacting functional units. J Neurosci 33:5718-5727. CrossRef Medline

McGeorge AJ, Faull RL (1989) The organization of the projection from the cerebral cortex to the striatum in the rat. Neuroscience 29:503-537. CrossRef Medline

McNaughton BL, Barnes CA, Gerrard JL, Gothard K, Jung MW, Knierim JJ, Kudrimoti H, Qin Y, Skaggs WE, Suster M, Weaver KL (1996) Deciphering the hippocampal polyglot: the hippocampus as a path integration system. J Exp Biol 199:173-185. Medline

Mizumori SJ, Puryear CB, Martig AK (2009) Basal ganglia contributions to adaptive navigation. Behav Brain Res 199:32-42. CrossRef Medline
Montgomery SM, Buzsáki G (2007) Gamma oscillations dynamically couple hippocampal $\mathrm{CA} 3$ and $\mathrm{CA} 1$ regions during memory task performance. Proc Natl Acad Sci U S A 104:14495-14500. CrossRef Medline

O'Keefe J, Dostrovsky J (1971) The hippocampus as a spatial map: preliminary evidence from unit activity in the freely-moving rat. Brain Res 34: 171-175. CrossRef Medline

O’Reilly RC, McClelland JL (1994) Hippocampal conjunctive encoding, storage, and recall: avoiding a trade-off. Hippocampus 4:661-682. CrossRef Medline

Packard MG, McGaugh JL (1996) Inactivation of hippocampus or caudate nucleus with lidocaine differentially affects expression of place and response learning. Neurobiol Learn Mem 65:65-72. CrossRef Medline

Penner MR, Mizumori SJ (2012) Neural systems analysis of decision making during goal-directed navigation. Prog Neurobiol 96:96-135. CrossRef Medline

Prusky GT, Douglas RM, Nelson L, Shabanpoor A, Sutherland RJ (2004) Visual memory task for rats reveals an essential role for hippocampus and perirhinal cortex. Proc Natl Acad Sci U S A 101:5064-5068. CrossRef Medline

Ragozzino ME, Ragozzino KE, Mizumori SJ, Kesner RP (2002) Role of the dorsomedial striatum in behavioral flexibility for response and visual cue discrimination learning. Behav Neurosci 116:105-115. CrossRef Medline

Reading PJ, Dunnett SB, Robbins TW (1991) Dissociable roles of the ventral, medial and lateral striatum on the acquisition and performance of a complex visual stimulus-response habit. Behav Brain Res 45:147-161. CrossRef Medline

Reep RL, Cheatwood JL, Corwin JV (2003) The associative striatum: organization of cortical projections to the dorsocentral striatum in rats. J Comp Neurol 467:271-292. CrossRef Medline

Saint-Cyr JA, Ungerleider LG, Desimone R (1990) Organization of visual cortical inputs to the striatum and subsequent outputs to the pallidonigral complex in the monkey. J Comp Neurol 298:129-156. CrossRef Medline

Schmitzer-Torbert N, Jackson J, Henze D, Harris K, Redish AD (2005) Quantitative measures of cluster quality for use in extracellular recordings. Neuroscience 131:1-11.

Schulz JM, Redgrave P, Mehring C, Aertsen A, Clements KM, Wickens JR, Reynolds JN (2009) Short-latency activation of striatal spiny neurons via subcortical visual pathways. J Neurosci 29:6336-6347. CrossRef Medline

Singer W, Gray CM (1995) Visual feature integration and the temporal correlation hypothesis. Annu Rev Neurosci 18:555-586. CrossRef Medline

Skaggs WE, McNaughton BL, Gothard KM, Markus EJ (1993) An information-theoretic approach to deciphering the hippocampal code. In: Advances in neural information processing systems (Hanson SJ, Cowan JD, Giles CL, eds), pp 1030-1037. San Mateo, CA: Morgan K.

Swanson LW (1981) A direct projection from Ammon's horn to prefrontal cortex in the rat. Brain Res 217:150-154. CrossRef Medline

Taube JS (1998) Head direction cells and the neurophysiological basis for a sense of direction. Prog Neurobiol 55:225-256. CrossRef Medline

Thorn CA, Graybiel AM (2014) Differential entrainment and learning-related dynamics of spike and local field potential activity in the sensorimotor and associative striatum. J Neurosci 34:2845-2859. CrossRef Medline

Thorn CA, Atallah H, Howe M, Graybiel AM (2010) Differential dynamics of activity changes in dorsolateral and dorsomedial striatal loops during learning. Neuron 66:781-795. CrossRef Medline

Tort AB, Kramer MA, Thorn C, Gibson DJ, Kubota Y, Graybiel AM, Kopell NJ (2008) Dynamic cross-frequency couplings of local field potential oscillations in rat striatum and hippocampus during performance of a T-maze task. Proc Natl Acad Sci U S A 105:20517-20522. CrossRef Medline

Voorn P, Vanderschuren LJ, Groenewegen HJ, Robbins TW, Pennartz CM (2004) Putting a spin on the dorsal-ventral divide of the striatum. Trends Neurosci 27:468-474. CrossRef Medline

White IM, Rebec GV (1993) Responses of rat striatal neurons during performance of a lever-release version of the conditioned avoidance response task. Brain Res 616:71-82. CrossRef Medline

Wiener SI (1993) Spatial and behavioral correlates of striatal neurons in rats performing a self-initiated navigation task. J Neurosci 13:3802-3817. Medline

Yin HH, Mulcare SP, Hilário MRF, Clouse E, Holloway T, Davis MI, Hansson AC, Lovinger DM, Costa RM (2009) Dynamic reorganization of striatal circuits during the acquisition and consolidation of a skill. Nat Neurosci 12:333-341. CrossRef Medline 